\title{
Aufsatz
}

Holger Afflerbach

\section{Kronprinz Rupprecht von Bayern im Ersten Weltkrieg}

DOI 10.1515/mgzs-2016-0002

Zusammenfassung: Kronprinz Rupprecht von Bayern (1869-1955), der Sohn König Ludwigs III. und Urenkel Ludwigs I., war während des Ersten Weltkriegs zuerst Armeeführer und kommandierte ab 1916 die nach ihm benannte Heeresgruppe an der Westfront, der 1918 bis zu 1,5 Millionen Soldaten unterstanden. Der Prinz war einer der prominentesten Heerführer der deutschen Armeen des Ersten Weltkriegs. Gleichzeitig war er als bayerischer Thronfolger auch ein politisch sehr gut vernetzter und deshalb teilweise außerhalb der militärischen Hierarchie stehender Mann. Der Beitrag untersucht die Fragen, wie Kronprinz Rupprecht den Krieg erlebte, ob sein Kommando ein tatsächliches oder ein dekoratives war, wie er die politischen und militärischen Optionen des Deutschen Reiches einschätzte, was er tat, um seine Ansichten zur Geltung zu bringen, und auch, wie er sein Handeln nach dem Krieg im Rückblick bewertete. Der Beitrag basiert auf Archivmaterial, unter anderem auf dem fast 4200-seitigen handschriftlichen Kriegstagebuch des Kronprinzen, und auf seiner ausgedehnten Korrespondenz.

Schlüsselwörter: Kronprinz Rupprecht von Bayern, Erster Weltkrieg, Kriegstagebuch, Korrespondenz

Während des Zweiten Weltkriegs war der ehemalige bayerische Kronprinz Rupprecht, der sich mit den Nationalsozialisten überworfen hatte, im italienischen Exil. Die Zwangsmuße gab ihm Zeit zur Reflektion, und so dachte er auch über den Ersten Weltkrieg nach, der ihm aus der Rückschau als der »dümmste aller Kriege ${ }^{1}$ erschien. Er hatte in diesem Krieg als bayerischer wie preußischer

1 Siehe Dieter Weiß, Kronprinz Rupprecht von Bayern. Eine politische Biografie, Regensburg 2007, S. 307. Diesen Beitrag habe ich während meiner Zeit als Stipendiat des Historischen Kollegs in München im Jahre 2012/13 geschrieben. Ich danke dem Historischen Kolleg für die Förderung und Dr. Jonathan Boff, Birmingham, Professor Dr. Lothar Machtan, Bremen, Dr. Markus Pöhlmann und PD Dr. John Zimmermann für ihre Kommentare und Verbesserungsvorschläge.

Kontakt: Holger Afflerbach, University of Leeds, UK, E-Mail: H.H.W.Afflerbach@leeds.ac.uk 
Generalfeldmarschall eine prominente Rolle gespielt und von 1914-1916 die 6. Armee und von 1916-1918 sogar eine nach ihm benannte Heeresgruppe an der Westfront befehligt. Im Jahre 1918 standen fünf Armeen und 1,5 Millionen Mann unter seinem Kommando. ${ }^{2}$

Kronprinz Rupprecht war aber nicht nur ein hochrangiger Soldat, der über sich nur den Kaiser und den Generalstabschef hatte, sondern außerdem noch der bayerische Thronfolger. Er wäre unter anderen Umständen nach dem Tod seines Vaters, König Ludwigs III., im Jahre 1921 König von Bayern geworden und hätte das Land bis zu seinem eigenen Tod im Jahre 1955 regiert. Als Thronfolger hatte Prinz Rupprecht eine Sonderstellung und stand partiell außerhalb der militärischen Hierarchie. Deshalb liegt es nahe zu vermuten, dass er im politischen wie im militärischen Bereich beträchtliche Möglichkeiten hatte, seine Ansichten durchzusetzen.

Doch war das tatsächlich der Fall? Der Prinz stand während des gesamten Krieges in oft scharfer Opposition zur politischen und militärischen Führung des Deutschen Reiches. Im Folgenden soll untersucht werden, wie seine Kritik und die von ihm vorgebrachten Alternativen $\mathrm{zu}$ bewerten waren und in welchem Umfang er sie zum Tragen bringen konnte.

Die Frage nach der Bedeutung des Einzelnen in einem komplexen Geschehen wie dem Ersten Weltkrieg ist naturgemäß schwer zu beantworten. Die Bedeutung der obersten Entscheidungsträger wie Wilhelm II. oder Hitler oder von historischen Ausnahmepersönlichkeiten wie Bismarck, Napoleon oder Lenin zu untersuchen ist sehr viel einfacher, als eine solide Antwort auf die Frage zu erhalten, welchen Spielraum der hochgestellte Einzelne hatte, der in der Rangfolge der Mächtigen nicht ganz, aber doch sehr weit oben rangierte und versuchte, die Abläufe zu beeinflussen. Paul Kennedy hat sich einer vergleichbaren Frage in seinem Buch »Engineers of Victory « zugewandt, in der er die mittlere Ebene der Alliierten im Zweiten Weltkrieg untersuchte. ${ }^{3}$ Von »Ingenieuren des Sieges « kann zwar im Fall des Ersten Weltkriegs und von Kronprinz Rupprecht nicht die Rede sein, wohl aber kann die Frage nach Alternativen in der deutschen Strategie und nach Verantwortlichkeiten an der Niederlage gestellt werden.

\footnotetext{
2 Bayerisches Hauptstaatsarchiv, Geheimes Hausarchiv (BayHStA, GHA), NL Rupprecht, Nr. 708, Kriegstagebuch, Eintrag vom 12.8.1918.

3 Paul Kennedy, Engineers of Victory: The Problem Solvers Who Turned the Tide in the Second World War, London, New York 2013; Titel der deutschen Ausgabe: Die Casablanca-Strategie, München 2012.
} 


\section{Die Forschungslage: Hagiografie und unverlässliche Editionen?}

Die Quellen- und Forschungslage zu Kronprinz Rupprecht ist ungewöhnlich gut. Es gibt mehrere umfangreiche Biografien des Prinzen, von denen hier nur die jüngste von Dieter Weiß erwähnt werden soll, und auch verschiedene, wenn auch nur kurze Untersuchungen seiner militärischen Tätigkeit im Ersten Weltkrieg. ${ }^{4}$ Diese Arbeiten kommen alle zu einem wohlwollenden Urteil über den Prinzen Kritiker haben ihnen sogar hagiografische Tendenzen vorgeworfen. ${ }^{5}$

Alle diese Arbeiten haben die gewaltige Menge an Primärquellen bislang noch nicht voll ausgeschöpft. Kronprinz Rupprecht dürfte einen der größten Nachlässe des Ersten Weltkriegs hinterlassen haben, der neben seinem vielseitigen Tagebuch auch eine umfängliche Privatkorrespondenz umfasst. ${ }^{6}$ Dieses Tagebuch, das 1929 veröffentlicht wurde, ist eine vielzitierte, aber problematische und unverlässlich editierte Quelle. ${ }^{7}$ Sie basiert auf einem handschriftlichen Manuskript, das sich im Geheimen Hausarchiv in München findet. In der Vergangenheit wurde die Vermutung geäußert, dass es sich bei dem vermeintlichen Original

4 Weiß, Kronprinz Rupprecht (wie Anm. 1); siehe auch Joe J. Heydecker, Kronprinz Rupprecht von Bayern. Ein Lebensbild, München 1953. Eine Fülle von Material enthält die sehr wohlwollende, noch zu Lebzeiten des Kronprinzen geschriebene Studie von Kurt Sendtner, Rupprecht von Wittelsbach, Kronprinz von Bayern. Pflaum, München 1954; sie ist wegen ihres Detailreichtums wertvoll und enthält, trotz hagiografischer und monarchistischer Tendenzen, bisweilen auch kritische Bemerkungen. Walter Goetz, Rupprecht Kronprinz von Bayern 1869-1955 - Ein Nachruf, München 1956. Eine sehr materialreiche und quellennahe Studie lieferte Stefan März, Das Haus Wittelsbach im Ersten Weltkrieg: Chance und Zusammenbruch monarchischer Herrschaft, Regensburg 2013. Speziell zu militärischen Aspekten: Hermann von Kuhl, Der Feldherr. In: Süddeutsche Monatshefte, 30 (1933), 4, S. 225-230 (offen hagiografisch); Dieter Storz, Kronprinz Rupprecht von Bayern - dynastische Heerführung im Massenkrieg. In: Monarchen und ihr Militär. Hrsg. von Winfried Heinemann und Markus Pöhlmann, Potsdam 2010, S. 45-57.

5 Besprechung von Lothar Machtan zu Weiß, Kronprinz Rupprecht (wie Anm. 1). In: H-Soz-Kult, 2.8.2007.

$6 \mathrm{Im}$ Bayerischen Hauptstaatsarchiv, Geheimes Hausarchiv, befindet sich nicht nur das Tagebuch Kronprinz Rupprechts, sondern auch eine Sammlung von Befehlen und amtlichen Schriftstücken seines Stabes sowie eine umfangreiche Korrespondenz, die er mit seinem Vater und seinem Onkel, mit dem bayerischen Ministerpräsidenten Hertling, dem Künstler Hildebrand, mit Max von Baden, also einem weiteren, später wichtigen Mitglied der deutschen Kronprinzenriege, und vielen anderen führte. Vielleicht ist dies der umfangreichste deutsche Privatnachlass des Ersten Weltkriegs. Zu der Edition durch Frauenholz siehe Anm. 7.

7 Kronprinz Rupprecht von Bayern, In Treue fest. Mein Kriegstagebuch, 3 Bde. Hrsg. von Eugen von Frauenholz, München 1929. 
um eine erste Abschrift handle. ${ }^{8}$ Sie umfasst 4197 handschriftliche Seiten, etwa im Umfang DIN A4. Hinzu kommt eine bisher nicht erfasste Fülle von Anlagen, auf die im Text hingewiesen wird und die sich ebenfalls im Archiv befinden. Sie umfassen amtlichen Schriftwechsel, unter anderem Befehle und Verordnungen der 6. Armee, der Heeresgruppe Kronprinz Rupprecht und der Obersten Heeresleitung (OHL). Schon der Herausgeber Eugen von Frauenholz hat, aus gutem Grund, die von Kronprinz Rupprecht offenbar ursprünglich geplante Veröffentlichung des Gesamtmaterials für unmöglich erklärt. ${ }^{9}$

Markus Pöhlmann hat in seinem Buch über die deutsche Militärgeschichtsschreibung 1914-1956 bereits auf einige Schwächen dieser Edition hingewiesen und durch Teiluntersuchungen aus den ersten beiden Kriegsmonaten sinnentstellende und beschönigende Auslassungen in der publizierten Fassung aufgezeigt. ${ }^{10}$ Diese Vorwürfe treffen auf die gesamte Edition zu. Sie könnten aber, wie Proben aus dem Gesamtmanuskript ergeben haben, noch wesentlich verschärft werden. Manche Eintragungen sind nicht nur beschönigt und verkürzt, sondern aus anderen Provenienzen hineinkopiert worden und haben mit dem ursprünglichen Text nichts mehr zu tun. ${ }^{11}$ Daher wird im Folgenden aus dem Manuskript zitiert und aus der Edition nur nach Abgleichung mit dem Original.

$\mathrm{Zu}$ dem Kriegstagebuch kommen noch die amtlichen Unterlagen der 6. Armee und seiner Heeresgruppe, die sich heute im Bayerischen Kriegsarchiv befinden, und weitere Nachlässe. Die Frage, was der Kronprinz und sein Stab im Ersten Weltkrieg im Einzelnen planten, taten und erlebten, könnte, unter Nutzung dieser Primärquellen, in einer umfassenden Geschichte (»thick description«) der

8 Besprechung von Markus Pöhlmann zu Weiß, Kronprinz Rupprecht (wie Anm. 1). In: Militärgeschichtliche Zeitschrift, 69 (2010), 2, S. 349-352.

9 Eugen von Frauenholz, Das Kriegstagebuch S.K.H des Kronprinzen von Bayern. In: Deutscher Offizier-Bund, 14.12.1928, Nr. 35.

10 Markus Pöhlmann, Kriegsgeschichte und Geschichtspolitik: Der Erste Weltkrieg. Die amtliche deutsche Militärgeschichtsschreibung 1914-1956, Paderborn [u.a.] 2002 (= Krieg in der Geschichte, 12), besonders S. 303-306.

11 An mehreren Stellen wurden beispielsweise die Aufzeichnungen des Ersten Stabschefs des Kronprinzen, Konrad Krafft von Dellmensingen, in das veröffentlichte Tagebuch integriert und die Originalaufzeichnungen des Kronprinzen ohne Kennzeichnung modifiziert oder weggelassen. Ein wichtiges, weil vielzitiertes Beispiel sind Rupprechts Ausführungen zum Gaskrieg. In der gedruckten Version verurteilt er den Ersteinsatz von Giftgas im Jahre 1915, weil dies eine unsympathische Waffe sei und außerdem, bei den herrschenden Windverhältnissen an der Westfront, der Gegner sie besser verwenden könne als die Deutschen. Diese Passagen fehlen im Original. Rupprecht, In Treue fest (wie Anm. 7), S. 305, Bd 1 (Eintrag vom 1.3.1915). Ein weiteres Beispiel ist ein Dialog mit Falkenhayn (Eintrag vom 21.4.1915), der sich im Original nicht findet. Letzterer ist offenbar ebenfalls aus dem Tagebuch Krafft von Dellmensingens übernommen, während Rupprecht im Original die Begebenheit ganz anders schilderte. 
Führung der 6. Armee und der Heeresgruppe Kronprinz Rupprecht dargestellt werden, die nicht nur klassische militärgeschichtliche, sondern auch - in Bezug auf den Stil der Kriegführung, den Sinn des Krieges und die Ansichten über den Gegner und die eigenen Soldaten - kulturgeschichtliche Aspekte zu untersuchen hätte.

\section{„Ein gebildeter Dilettant»? Konnte der Prinz seine Oberbefehlshaberfunktion ausfüllen?}

Dieser Aufsatz verfolgt aber ein anderes Ziel. Im Folgenden soll der politische und militärische Handlungsspielraum des Prinzen im Krieg näher ausgeleuchtet werden. Diese Frage hat eine über den Einzelfall hinausreichende Bedeutung, da Rupprecht als Prinz und Armeeführer keine Ausnahme war, sondern eine typische Erscheinung für den Ersten Weltkrieg, der oft als der »Untergang des Alten Europa« bezeichnet wird. Dieser Weltkrieg war auch ein Krieg der Könige und Prinzen. Oft wird auf die dynastischen Verbindungen zwischen den europäischen Herrscherfamilien vor 1914 hingewiesen, auf den »Willy-Nicky«-Briefwechsel zwischen Kaiser und Zar, oder die Verbindungen zwischen dem deutschen und britischen Königshaus. Doch nach Kriegsbeginn kämpften nicht nur die Völker, sondern auch die Herrscherfamilien gegeneinander. Wie in früheren Kriegen, und wohl zum letzen Mal in der europäischen Geschichte, wurden viele Prinzen aus den Herrscherhäusern zu Armeeführern und hohen Offizieren ernannt. Dies war auch im Deutschen Reich der Fall, um so mehr deshalb, weil die Bundesstaaten, die bis auf die Stadtstaaten Monarchien waren, ein Kontingentheer stellten und Bayern, ebenso wie Preußen, Sachsen und Württemberg, eigene Armeeorganisationen unterhielten. Sie wollten auch Mitglieder der eigenen Fürstenfamilien in hohen Kommandopositionen sehen.

Eine Frage, die sich bei diesem »Krieg der Prinzen« direkt stellt, ist, ob die kaiserlichen, königlichen und prinzlichen Oberbefehlshaber befähigt waren, ihre Position fachlich auszufüllen oder ob sie eine rein dekorative Funktion innehatten und die tatsächliche Arbeit anderen, nämlich ihren Stabschefs, überlassen mussten. ${ }^{12}$ Kronprinz Rupprecht äußerte sich Ende $1915 \mathrm{zu}$ diesem Problem und kritisierte, dass

12 Diese Frage stellte sich auch für kommandierende Generäle und ihre Stabschefs; das berühmteste Beispiel dürfte das Verhältnis zwischen Hindenburg und Ludendorff sein. Dazu Manfred Nebelin, Ludendorff. Diktator im Ersten Weltkrieg, München 2010; Wolfram Pyta, Hindenburg. Herrschaft zwischen Hohenzollern und Hitler, München 2007. 
»unsere Vorschriften [...] eben auf zwei Kategorien von Oberbefehlshabern zugeschnitten [sind]: Fürstlichkeiten, die den Dienst nicht im vollen Umfange beherrschen, oder alte und daher nicht mehr voll leistungsfähige Generäle. « ${ }^{13}$

Da dies so sei, hätten die Generalstabsoffiziere »viel zu weitgehende« Befugnisse.

Die Frage, ob Prinzen wie Kronprinz Rupprecht selber und kompetent führten, kann aber nicht pauschal, sondern nur individuell beantwortet werden, da dies von ihren militärischen Fähigkeiten und auch von ihrem Durchsetzungswillen abhing. Über letzteren verfügte Kronprinz Rupprecht, der zu den prominentesten fürstlichen Oberbefehlshabern im deutschen Heer des Ersten Weltkriegs gehörte. Er wurde 1869 geboren und war der Sohn König Ludwigs III. und Urenkel Ludwigs I. Er hatte vor dem Ersten Weltkrieg weite Reisen unternommen und interessierte sich, darin seinem Urgroßvater Ludwig I. sehr ähnlich, für Kunst und Kultur. Sein Denken war aber nicht frei von zeitgemäßen und bisweilen auch rassistischen Stereotypen. ${ }^{14}$ Er hatte sein Abitur in einem öffentlichen Gymnasium abgelegt, was ein Novum darstellte, danach die vor 1914 typische Universalausbildung für Prinzen erfahren, Universitätskurse in verschiedenen Fächern besucht sowie im Schnelldurchgang, die typischen Stationen der militärische Laufbahn einschließlich des Besuchs der Kriegsakademie absolviert. Im Jahre 1913 wurde er als Nachfolger seines Onkels Leopold Generaloberst und für den Kriegsfall als Oberbefehlshaber eingeplant. Dies war das Maximum, das er in Friedenszeiten erreichen konnte. Sicherlich ist das Urteil von Dieter Storz berechtigt, dass die soldatische Ausbildung des Prinzen nicht so solide war wie die eines routinierten Generalstabsoffiziers. ${ }^{15}$ Und trotzdem war Kronprinz Rupprecht kein militärischer Laie.

Erich Ludendorff urteilte über den Kronprinzen in seinen »Kriegserinnerungen« wie folgt:

13 BayHStA, GHA, NL Rupprecht, Nr. 703, Kriegstagebuch, Eintrag vom 14.11.1915.

14 Der Kronprinz war keineswegs frei von zeitgenössischen Stereotypen in der Beurteilung anderer Völker, die, wenn man heutige Maßstäbe anlegt, als rassistisch bezeichnet werden können. Siehe dazu die - polemische - Auswertung seiner Reisebeschreibungen und sonstigen Äußerungen von S. Wiguläus Dräxelmayr, Kronprinz Rupprecht von Bayern: Wie rassistisch darf ein »Nazigegner« sein? In: <www.hagalil.com/archiv/2012/11/04/rupprecht-von-bayern/print/> (letzter Zugriff 20.7.2013). Viele Beispiele für sein entsprechend gefärbtes Vokabular finden sich auch in seinen Kriegstagebüchern.

15 Dieter Storz, »Dieser Stellungs- und Festungskrieg ist scheußlich!« Zu den Kämpfen in Lothringen und in den Vogesen im Sommer 1914. In: Der Schlieffenplan. Analysen und Dokumente. Im Auftrag des Militärgeschichtlichen Forschungsamtes und der Otto-von-Bismarck-Stiftung hrsg. von Hans Ehlert, Michael Epkenhans und Gerhard P. Groß, Paderborn [u.a.] 2006 (= Zeitalter der Weltkriege, 2), S. 161-204, hier S. 166. 


\begin{abstract}
»[Rupprecht] war aus Pflichtgefühl Soldat. Seine Neigungen waren keine soldatischen. Er ging an seine hohe militärische Stellung und ihre Aufgaben mit großem Ernste heran und hat, gestützt auf seine vortrefflichen Generalstabschefs [...], den großen Anforderungen entsprochen, die an einen Oberbefehlshaber zu stellen sind. «16
\end{abstract}

War Kronprinz Rupprecht, wie man dieser Äußerung entnehmen könnte, ein widerwilliger Soldat? In seinem Tagebuch schilderte er den Kriegsbeginn im August 1914 als Zeit nervöser Bedrückung und Schlaflosigkeit; dies wirkt nicht, als wenn er mit großer Begeisterung ins Feld gezogen wäre. ${ }^{17}$ Er wurde erst ruhiger, als er schließlich im Zug an die Front saß. Hier setzt sein Kriegstagebuch ein. Es besteht aus Notizen, die sich der Prinz während jedes einzelnen Tages machte und aus denen sein Kriegsalltag über vier Jahre hinweg rekonstruiert werden könnte. Die Tagebücher zeigen, dass der Prinz sich sehr detailliert mit den militärischen Vorgängen beschäftigte. ${ }^{18}$ Vielleicht war er nicht gern Soldat - die Tagebücher lassen diesen Schluss übrigens nicht zu -, aber er war äußerst pflichtbewusst und suchte seine Position eigenständig auszufüllen. Seine Aufzeichnungen lassen sich auch schwer mit der von Oberst Walter Nicolai, dem Chef des militärischen Nachrichtendienstes, nach dem Krieg erhobenen Behauptung, Kronprinz Rupprecht sei »militärisch nur ein gebildeter Dilettant" gewesen, in Einklang bringen. ${ }^{19}$

Die ursprüngliche Funktion dieser Aufzeichnungen ist unklar. Der Prinz hat sie vermutlich als Gedächtnisstütze angelegt, die ihm helfen sollte, militärische Entscheidungen zu fällen und dabei auch in den Einzelheiten sicher informiert zu sein. Tatsächlich zeigte sich der Prinz, nach Ansicht seiner Offiziere, über die Lage bei seiner Armee (und später Heeresgruppe) gut unterrichtet..$^{20}$ Neben der Bereitschaft, sich mit den militärischen Vorgängen auch im Detail zu befassen, hatte Kronprinz Rupprecht auch den ausgeprägten Willen, sich durchzusetzen. Der Prinz war sehr selbstbewusst und meinungsfreudig - einer seiner Offiziere nannte ihn ein "starkes Temperament «"1 - und oft gänzlich anderer Ansicht als der Generalstab, und zwar sowohl was taktische Details, die seine Armee oder Heeresgruppe betrafen, als auch was die großen strategischen Fragen des Krieges anging.

16 Erich Ludendorff, Meine Kriegserinnerungen 1914-1918, Berlin 1919, S. 216.

17 BayHStA, GHA, NL Rupprecht, Nr. 703, Kriegstagebuch, Eintrag vom 14.11.1915.

18 Siehe auch Wolfgang Förster, Ein fürstlicher Heerführer. In: Deutscher Offizier-Bund, 15.5.1929, der das Tagebuch als "vollgültiges Zeugnis« dafür nahm, dass Kronprinz Rupprecht »nicht nur das nach außen hin sichtbare Firmenschild abgab«.

19 Sonderarchiv Moskau, NL Nicolai, 1414-1-17.

20 März, Das Haus Wittelsbach (wie Anm. 4), S. 329-331.

21 Kuhl, Der Feldherr (wie Anm. 4), S. 225. 


\section{Ein auf bayerische Belange verengter Blickwinkel? Kronprinz Rupprecht als bayerischer Föderalist}

Diese strategischen Einschätzungen des Prinzen sind natürlich von erstrangigem Interesse. Doch zunächst muss hier erwähnt werden, dass sie sehr stark, und mehrfach auch zu prononciert, durch sein Selbstverständnis als bayerischer Thronfolger geprägt wurden. Rupprecht fühlte sich als Hüter des Reichsföderalismus und vor allem der bayerischen Stellung im Reich und als Kämpfer gegen unitarische Tendenzen, und zwar in politischer wie auch in militärischer Hinsicht. Er wollte die bayerische Eigenständigkeit bewahren und stärken. Rupprecht war zwar überzeugter Reichsdeutscher und kein Separatist, aber er war eifersüchtig auf die Wahrung der bayerischen Stellung im Reiche bedacht und auch in Protokollfragen von extremer Empfindlichkeit.

Diese Haltung hatte militärische wie politische Auswirkungen. Um bei den militärischen anzufangen: Rupprecht legte großen Wert darauf, bayerische Truppen zu befehligen, und verteidigte die Eigenständigkeit des bayerischen Heeres bei jeder sich bietenden Gelegenheit. Seine 6. Armee war auch ursprünglich aus mehrheitlich bayerischen Divisionen zusammengesetzt und dies blieb, trotz aller Truppenverlegungen während des Krieges, in Teilen so bestehen. Der Krieg und der in der Verfassung festgelegte Oberbefehl des Kaisers im Kriegsfall und damit die Verfügungsgewalt des im Namen des Kaisers agierenden Generalstabs hatten aber eine gewaltige zentralisierende Wirkung, die Kronprinz Rupprecht nicht aufhalten konnte. Sein Streben nach Wahrung der bayerischen Eigenständigkeiten in militärischen Dingen kam daher oft in vergleichsweise nachrangigen Fragen zum Ausdruck. Dies waren in vielen Fällen Personalfragen, etwa die landsmannschaftliche Zugehörigkeit ihm unterstellter Offiziere, über deren Ernennung oder Abberufung er zu befinden hatte. Er verbat sich das Hineinregieren des Generalstabs und des Militärkabinetts, also der preußischen Personalbehörde für Offizierangelegenheiten, in bayerische Belange. Rupprechts Wunsch, die bayerische Eigenständigkeit zu bewahren, ging so weit, dass er im Sommer 1916, als er zum Oberbefehlshaber einer nach ihm benannten Heeresgruppe ernannt wurde, Enttäuschung äußerte: Er hätte es bevorzugt, Oberbefehlshaber einer rein bayerisch zusammengesetzten Armee zu werden.

\section{Kronprinz Rupprecht und sein Stab}

Hier ist auch ein kurzer Blick auf seinen Stab notwendig, da Kronprinz Rupprecht seine militärischen Entscheidungen in Abstimmung mit seinen engsten Mitarbei- 
tern traf, vor allem mit seinen Stabschefs, die, neben dem Oberbefehlshaber, die zentralen Figuren eines Armeestabes waren. Rupprecht hatte während des Krieges derer drei, nämlich zuerst General Krafft von Dellmensingen, dann Oberst Graf Lambsdorff und schließlich Generalleutnant Hermann von Kuhl.

Krafft von Dellmensingen, ein bayerischer Offizier, war für Kronprinz Rupprecht ein alter Bekannter, denn er war mit ihm an der Generalstabsakademie gewesen und freute sich über die Ernennung, da er Krafft »als klugen und energischen Menschen schätzen gelernt hatte ${ }^{22}$ und in ihm einen Freund sah. ${ }^{23}$ In einer Hinsicht war das Gespann Rupprecht-Krafft allerdings nicht ideal zusammengesetzt: Krafft war zwar ein guter Generalstäbler, ${ }^{24}$ hatte aber starke antipreuBische Ressentiments, die, nach Aussage seines Biografen, von seiner hochemotionalen und ehrgeizigen Gemahlin ständig weiter aufgeheizt wurden. ${ }^{25} \mathrm{Krafft}$ hatte massiven und konstanten Argwohn gegen preußische Bevormundungstendenzen (»Uns hat man einfach nicht geglaubt! - Das ist charakteristisch. Erst musste der Preuße kommen! $\star^{26}$ ), was ähnliche Tendenzen des Prinzen in unheilvoller Weise verstärkte und die Zusammenarbeit mit dem »preußischen« Generalstabschef Erich von Falkenhayn erschwerte.

Zum Ärger des Prinzen wurde Krafft im Mai 1915 zum Alpenkorps versetzt, was Rupprecht und Krafft für eine antibayerische Intrige Falkenhayns hielten, für die es aber keine Anzeichen gab. In Wahrheit wurde das Alpenkorps, für dessen Führung Krafft sehr qualifiziert war, wegen des drohenden Kriegseintritts Italiens aufgestellt, der dann am 23. Mai 1915 tatsächlich erfolgte. ${ }^{27}$ Krafft wurde durch Gustav Freiherr von der Wenge genannt Lambsdorff ersetzt, mit dem Rupprecht aber nicht zurechtkam und den er als Spion der OHL und Falkenhayns sowie als »kalten Höfling « empfand, der ihn von der Führung seiner Armee auszuschließen versuche. Im Herbst 1915 ließ er Lambsdorff ablösen, der durch Hermann von Kuhl ersetzt wurde. Kuhl galt als einer der fähigsten deutschen Generalstabsoffiziere -

22 BayHStA, GHA, NL Rupprecht, Nr. 703, Kriegstagebuch, Eintrag vom 14.11.1915.

23 Ebd., Nr. 702, Kriegstagebuch, Eintrag vom 19.5.1915.

24 Dazu die gut recherchierte Biografie von Thomas Müller, Konrad Krafft von Dellmensingen (1862-1953). Porträt eines bayerischen Offiziers, München 2002; siehe auch Storz, »Dieser Stellungs- und Festungskrieg ist scheußlich!« (wie Anm. 15), S. 166.

25 Müller, Konrad Krafft von Dellmensingen (wie Anm. 24).

26 Storz, »Dieser Stellungs- und Festungskrieg ist scheußlich!« (wie Anm. 15), S. 196.

27 Dazu Holger Afflerbach, Vom Bündnispartner zum Kriegsgegner. Ursachen und Folgen des italienischen Kriegseintritts im Mai 1915. In: Der Kriegseintritt Italiens im Mai 1915. Hrsg. von Johannes Hürter und Gian Enrico Rusconi, München 2007 (= Schriftenreihe der Vierteljahrshefte für Zeitgeschichte, Sondernummer), S. 53-69, sowie Holger Afflerbach, »Vani e terribili olocausti di vite umane«. Luigi Bongiovannis Warnungen vor dem Kriegseintritt Italiens im Jahre 1915. In: ebd., S. 85-98. 
sein Name wird normalerweise in einem Atemzug mit Ludendorff, Schulenburg, Lossberg, Groener und Seeckt als den größten operativen Begabungen der preußisch-deutschen Armeen des Ersten Weltkriegs genannt - und wurde später auch vom Parlamentarischen Untersuchungsausschuss der Weimarer Nationalversammlung als Sachverständiger für militärische Fragen des Weltkriegs berufen. Er war, wie Ludendorff meinte, ein Mann mit »eisernen Nerven ${ }^{28}$ und gleichzeitig diplomatischem Geschick, und er war promovierter Philologe, was den Interessen des Prinzen entgegenkam, da beide bei Tisch nicht über das Tagesgeschäft, sondern über Kunst diskutierten. ${ }^{29}$

Als Oberbefehlshaber oblag Kronprinz Rupprecht auch die Inspektion der unterstellten Einheiten. Er kam dieser Aufgabe nach, lehnte aber eine übertriebene Besuchstätigkeit ab und sah seinen Platz als Oberbefehlshaber am Kartentisch. ${ }^{30}$ Er saß vor der Landkarte und dem Telefon und stand einem Stab vor, der die Korps und Divisionen, die seiner Armee zugeteilt waren, befehligte, und von diesen wiederum mit Meldungen überschüttet wurde. Die Tagebücher geben darüber, vor allem über Feindmeldungen und Gefangenenbefragungen, erschöpfend Aufschluss. Das Armeeoberkommando seinerseits erhielt Weisungen von der OHL.

Dem Stab gehörten dann noch eine Reihe weiterer Offiziere an, zu denen beispielsweise auch Hauptmann Franz Halder zählte, der später Generalstabschef unter Hitler werden sollte, in dem Stab aber keine Gelegenheit hatte, »operative Talente zu zeigen «. ${ }^{31}$ Die Arbeitsatmosphäre in Prinz Rupprechts Stab war gut, was wesentlich am Prinzen lag, der unter Druck nicht unruhig oder nervös wurde. ${ }^{32}$ Er war offenbar im Umgang freundlich, aber nur, solange man ihn als Königliche Hoheit respektierte. Der Prinz war überaus distanziert, was auch aus

28 Ludendorff, Meine Kriegserinnerungen (wie Anm. 16), S. 217.

29 Sendtner, Rupprecht von Wittelsbach (wie Anm. 4), S. 252; zum Leben im Hauptquartier siehe auch März, Das Haus Wittelsbach (wie Anm. 4), S. 331.

30 Kuhl, Der Feldherr (wie Anm. 4); siehe auch BayHStA, GHA, NL Rupprecht, Nr. 703, Kriegstagebuch, Eintrag vom 19.10.1915.

31 BayHStA, GHA, NL Rupprecht, Nr. 724, Kuhl an Rupprecht, 21.12.1938.

32 Kuhl an Rupprecht, 10.2.1919: "Dass unser Stab gut und zuverlässig und ruhig arbeiten konnte, war das große Verdienst Eurer Könglichen Hoheit. Immer wieder habe ich dies meinen Herren vorgehalten. Eure Königliche Hoheit haben sich nicht in Kleinigkeiten eingemischt, sondern die große Lage im Auge gehabt, die Ereignisse stets soweit reifen lassen, bis es Zeit war, die Entscheidung zu treffen, und diese dann schnell und sicher getroffen.« Diese Äußerung aus einem an den Prinzen gerichteten Brief mag als schmeichlerisch abgetan werden, wird aber durch andere Quellenaussagen bestätigt. Übereinstimmende Äußerungen, etwa von Franz Halder, finden sich bei März, Das Haus Wittelsbach (wie Anm. 4), S. 328-333. 
seinen Vorkriegsqualifikationsberichten hervorgeht. ${ }^{33}$ Insgesamt war er ein sehr strenger und auf seine Würde und Stellung außerordentlich bedachter Mensch. ${ }^{34}$

Seine private Seite ist für Historiker schwer $\mathrm{zu}$ fassen. Das Tagebuch ist fast vollständig den militärischen Geschehnissen gewidmet. An den wenigen Stellen, die sich mit anderem beschäftigen als Militär und Politik, ging es gelegentlich um derbe Anekdoten und Landsknechtshumor, ${ }^{35}$ meistens jedoch um Ärger mit seinem Vater. ${ }^{36}$ Der Kronprinz hatte übrigens während des Krieges Beziehungen mit französischen Damen. Er war verwitwet, daher konnte man ihm, anders als im ähnlich gelagerten Fall des Kronprinzen Wilhelm, keinen Ehebruch vorwerfen. Trotzdem wurden seine Liebschaften als Ärgernis, als Geschmacklosigkeit und sogar als Sicherheitsrisiko empfunden. Offenbar wurde bei den Generälen der Westfront und auch im Bayerischen Kriegsministerium das Thema des "unpassenden Umgangs « des Kronprinzen sehr breit und sehr kritisch diskutiert. ${ }^{37}$

Aus den zahlreichen erhaltenen Akten der 6. Armee und der Heeresgruppe Kronprinz Rupprecht geht hervor, dass das militärische Tagesgeschäft im Wesentlichen in der Hand des Chefs des Stabes, Kuhl, lag. In der zweiten Kriegshälfte ist dessen Unterschrift auf den Schriftstücken fast allgegenwärtig. Kronprinz Rupprecht und seine Stabschefs gaben den Befehlshabern unterstellter Einheiten viel Freiheit und verlangten gleiches auch von ihrer übergeordneten Kommandobehörde. Rupprecht war, so schrieb sein zeitgenössischer Biograf Sendner, ein angenehmer Vorgesetzter und ein unbequemer Untergebener. ${ }^{38}$ Der Prinz und sein Armee- und später Heeresgruppenstab reagierten ausgesprochen allergisch, wenn ihre Ratschläge und Empfehlungen missachtet wurden, wenn der Generalstab es besser zu wissen glaubte und in ihren Befehlsbereich hineinregierte. Diese Konflikte und die damit zusammenhängenden Fragen gingen oft vom taktischen ins strategische über und verdienen deshalb eine nähere Behandlung. Und hierum soll es im Folgenden gehen: Nicht um das militärische Alltagsgeschäft in einem Armeestab während des Krieges, sondern um Kronprinz Rupprechts Kritik an der deutschen Strategie. Schon in den ersten Wochen des Krieges sollte sich

33 Qualifikationsberichte in Bay HstA, KA, 47534. Siehe auch Kuhl, Der Feldherr (wie Anm. 4), S. 230.

34 Ähnlich beschrieb ihn sein Großneffe, Christoph Prinz von Bayern, am 1.7.2013 dem Verfasser. 35 BayHStA, GHA, NL Rupprecht, Nr. 701, Kriegstagebuch, Einträge vom 18.2. und 27.2.1915 (letzterer eine Episode über Zekki Pascha und eine französische Prostituierte).

36 Beispiel: ebd., Nr. 708, Kriegstagebuch, Eintrag vom 2.11.1918: »All seinen Groll lässt mein Vater stets an mir aus. Vor den übrigen Leuten krebst er, wenn er den geringsten Widerstand gegen seinen Willen findet."

37 Sonderarchiv Moskau, NL Nicolai, 1414-1-17; März, Das Haus Wittelsbach (wie Anm. 4), S. 333.

38 Sendtner, Rupprecht von Wittelsbach (wie Anm. 4), S. 119. 
hier ein Muster zeigen. Der Prinz kritisierte Aktionen, an denen er selber mitwirkte und die er manchmal sogar selbst vorantrieb.

\section{Rupprechts Kritik an Moltke im September 1914}

Gravierende Gegensätze zwischen Kronprinz Rupprecht und seinem Stabschef Krafft einerseits und der Obersten Heeresleitung, also Generaloberst Helmuth von Moltke (dem Jüngeren), andererseits sollten sich schon wenige Wochen nach Kriegsausbruch herausbilden. Kronprinz Rupprecht befehligte seit Kriegsbeginn die 6. Armee und zeitweise wurde ihm auch die 7. Armee unterstellt; dies waren über 300000 Soldaten. Beide Armeen waren zuständig für den Schutz der deutschen Grenze gegen Frankreich. Sie sollten Elsass-Lothringen gegen einen zu erwartenden französischen Angriff verteidigen, im Idealfall etwas zurückweichen, gegnerische Kräfte binden und die Franzosen hindern, Truppen abzuziehen, um dem gleichzeitig durch Belgien nach Nordfrankreich vorrückenden deutschen rechten Flügel entgegentreten zu können. Dies sollte auch dem großen Umfassungsplan zugute kommen. Am 20. August 1914 kam es zu einer Begegnungsschlacht, da zunächst die französische Armee nicht vorrückte und Rupprecht und Krafft sich daraufhin selbst zum Angriff entschlossen. Als sie offensiv wurden, griffen die Franzosen doch an.

In diesen sogenannten Grenzschlachten wurden die Franzosen geschlagen; der Sieg bei Saarburg und Mönchingen wurde als großer Triumph des Kronprinzen und Kraffts gefeiert. Dann befahl der Generalstab Kronprinz Rupprechts Truppen, die Offensive Richtung Épinal fortzusetzen, also die für undurchdringlich gehaltene französische Festungslinie anzugreifen. Die Truppen des Kronprinzen konnten diese Aufgabe nicht lösen, sie waren dafür weder zahlenmäßig ausreichend, noch verfügten sie über das notwendige Belagerungsgerät. Auch stellte sich hier die Frage nach dem Sinn des Unternehmens, denn die Stärke der französischen Festungslinie war der Grund für die Verletzung der belgischen Neutralität gewesen.

In den Kämpfen wurden zwischen 350000-400000 deutsche und französische Soldaten verwundet oder getötet. ${ }^{39}$ Trotz dieser blutigen Verluste waren Oberbefehlshaber und Truppen im August 1914 in Siegesstimmung und folgten dem sich zurückziehenden Gegner auf Straßen, die übersät waren mit zurückgelassenem militärischen Gerät. Für einen Augenblick glaubte die gesamte deut-

39 Pöhlmann, Kriegsgeschichte und Geschichtspolitik (wie Anm. 10), S. 284-321; Storz, »Dieser Stellungs- und Festungskrieg ist scheußlich!« (wie Anm. 15), S. 204. 
sche Armee Ende August 1914, der Feldzug sei bereits gewonnen. Kronprinz Rupprecht hatte mit der Schlacht bei Saarburg den ersten Sieg dieses Krieges errungen. Er wurde dadurch populär, und im Rathaus von Neuburg an der Donau gab es sogar einen hölzernen Kronprinz Rupprecht, in den man gegen Zahlung von 50 Pfennig einen Nagel schlagen durfte. ${ }^{40}$ Dies, ebenso wie eine Flut von Feldpostkarten mit seinem Bild, sind Zeichen dafür, wie populär der Prinz aufgrund seiner Heerführerschaft war, nämlich in einem Ausmaß, das seinem Vater, König Ludwig III., schon eifersüchtige Sorgen bereitete.

Später folgte die Kritik. In der Zwischenkriegszeit wurden diese »Grenzschlachten « als »dynastische Luxusschlacht « kritisiert, ${ }^{41}$ als Profilierungsversuch des bayerischen Prinzen und als Verschwendung von Kräften, die dann auf dem entscheidenden rechten Flügel gefehlt hätten. Dies traf sicher zu und Kronprinz Rupprecht kritisierte später diese Angriffe auf die französische Festungslinie, machte aber Moltkes ziellose Führung dafür verantwortlich. Ein Teil der Schuld lag aber, gerade wegen des weiten Spielraums, den seine Armeeführung hatte, bei ihm selbst und seinem Stab, da sie aus soldatischem Aktivismus heraus entschieden hatten, anzugreifen. Den Generalstab wiederum traf die Verantwortung dafür, den Angriff fortzusetzen, statt die Truppen nach erfolgreicher Abwehr der französischen Offensive auf den rechten Flügel oder aber an die Ostfront $\mathrm{zu}$ verschieben, wo sie bald schon dringend gebraucht worden wären. In diesen Wochen und während der Marneschlacht ließ der Generalstab den einzelnen Armeen sehr viel Handlungsspielraum - offenbar zu viel.

Hier äußerte, erstmalig in diesem Krieg, Kronprinz Rupprecht massive Kritik an der Führung. Er empfand Moltkes Führung als »dilettantisch« und kritisierte auch dessen Mitarbeiter, die »die Mängel ihres Chefs nicht ersetzen « könnten. ${ }^{42}$ Die Krise an der Marne endete mit Moltkes Ablösung. Er wurde durch den bisherigen Preußischen Kriegsminister Erich von Falkenhayn ersetzt, der als Chef der 2. OHL in die Geschichtsbücher eingegangen ist.

\section{Kronprinz Rupprecht in der Ära Falkenhayn}

Falkenhayn war im Generalstab ein Außenseiter, der durch kaiserliche Protektion in sein Amt gelangt war. Angefeindet von allen Seiten, so von Hindenburg

40 Es handelt sich um eine Art großen Schrank mit einer Relieffigur des Kronprinzen; dieser befindet sich heute im Bayerischen Armeemuseum in Ingolstadt.

41 Storz, »Dieser Stellungs- und Festungskrieg ist scheußlich!« (wie Anm. 15), S. 178.

42 BayHStA, GHA, NL Rupprecht, Nr. 699, Kriegstagebuch, Eintrag vom 16.9.1914. 
und Ludendorff, war auch sein Verhältnis zu Kronprinz Rupprecht von Anfang an nicht gut und wurde bald schon katastrophal schlecht. Der Prinz tat nun alles, um Falkenhayns Stellung $\mathrm{zu}$ unterminieren. Seine Abneigung gegen Falkenhayn ist das immer wiederkehrende Hauptmotiv der ersten zwei Jahre und der ersten 2000 Seiten seines Kriegstagebuchs. Seine Mitarbeiter sprachen davon, dass Rupprecht Falkenhayn "glühend hasste «. ${ }^{43}$ Was waren die Gründe für diese Abneigung? In ihr verschmolzen menschliche Faktoren mit sachlichen Gegensätzen. Beides muss aber voneinander getrennt betrachtet werden, um die Stichhaltigkeit von Kronprinz Rupprechts Opposition beurteilen zu können.

Vieles spricht dafür, dass der Prinz seine starke emotionale Abneigung gegen Falkenhayn nicht kontrollieren konnte und dass ihm dies eine sachliche und unvoreingenommene Bewertung von dessen Maßnahmen erschwerte. Der Prinz konnte Falkenhayns »spöttelnde Überlegenheit « ${ }^{44}$ schlicht nicht ertragen. Wenn Falkenhayn etwa bei einem Besuch in seinem Hauptquartier im Herbst 1914 fragte, warum bei der 6. Armee bisher so wenig Generäle gefallen seien, wo doch der Tod vieler von ihnen die Truppe motivieren würde, empfand Rupprecht dies als zynisch und beleidigend; überhaupt sah er in sehr vielen Anordnungen der OHL gegen ihn gerichtete Spitzen und in Kritiken Falkenhayns Zweifel an seinen Maßnahmen. In diesem Eindruck, der sich oft $\mathrm{zu}$ einem generellen Lamento gegen die sich in Falkenhayn personifizierende preußische Rücksichtslosigkeit und Besserwisserei steigerte, wurde der Prinz von seinem Stabschef Krafft nach Kräften sekundiert und bestärkt. Eine weitere bedeutsame Ursache der Verstimmung war, dass der Prinz Falkenhayn rhetorisch nicht gewachsen war, sodass für ihn, bei seinem stark ausgeprägtem Selbstgefühl, jede Besprechung zur Qual wurde. Kronprinz Rupprecht kommentierte dies während der Sommeschlacht 1916 wie folgt:

»Die Verhandlungen mit Falkenhayn sind stets sehr unerquicklich, da er einem immer das Wort im Munde herumdreht und auf Überlistung bedacht ist, anstatt offen heraus zu sagen, wie die Dinge stehen und was er demnach für nötig erachtet. Man könnte oft glauben, es mit einem Schacherjuden zu tun zu haben. $\ll^{45}$

Die Wortwahl ist abstoßend, aber die Begebenheit dokumentiert, wo der Prinz die Probleme sah. Er meinte, Falkenhayn fehle es an Geradlinigkeit und kaschiere mit

43 Holger Afflerbach, Falkenhayn. Politisches Denken und Handeln im Kaiserreich, München 1994 (= Beiträge zur Militärgeschichte, 42), S. 215.

44 Sonderarchiv Moskau, NL Nicolai, 1414-1-13.

45 BayHStA, GHA, NL Rupprecht, Nr. 704, Kriegstagebuch, Eintrag vom 12.7.1916. 
geschickter Rhetorik seine Unfähigkeit. Er empfand den Umgang mit dem »Spieler« Falkenhayn, dem - fälschlich - vom Glücksspiel herrührende Millionenschulden nachgesagt wurden, ${ }^{46}$ als menschlich unangenehm.

Neben diesem persönlichen - und wahrscheinlich die Abneigung des Prinzen dominierenden - Gegensatz gab es noch einen gravierenden sachlichen Konflikt: In den Verhandlungen während der Schlacht an der Somme und auch in vielen anderen Fällen stritten sich Falkenhayn und Rupprecht um vom Generalstab verlangte Kräfteabgaben der 6. Armee. Hier bestand ein unvermeidlicher Gegensatz zwischen der OHL und allen unterstellten Armeen, der sowohl taktische als auch strategische Aspekte hatte. Falkenhayn zog Kräfte aus der Armee des Kronprinzen ab, die dieser, oft zu Recht, zur Erfüllung seines Kampfauftrags zu brauchen glaubte. Doch Kronprinz Rupprecht weigerte sich, über die Grenzen seiner Armee hinaus aufs Ganze zu blicken. Er gelangte nicht zu der Einsicht, dass Falkenhayn mit knappen Kräften einen Mehrfrontenkrieg organisieren musste und die Decke überall zu kurz war. Hier zeigten sich die Grenzen seines strategischen Verständnisses und auch, dass die Abneigung gegen Falkenhayn sein Urteilsvermögen beeinträchtigte.

Gleichzeitig und dazu im Gegensatz stehend warf der Prinz in seinem Tagebuch dem Generalstabschef immer wieder - jedoch nicht von Angesicht zu Angesicht - vor, nicht alle Kräfte zum Entscheidungsschlag zusammenzufassen und den großen Wurf nicht zu wagen. In der Ära Falkenhayn, also von 1914 bis Sommer 1916, glaubte Rupprecht an die Möglichkeit eines militärischen Sieges. Er lehnte deshalb Falkenhayns Strategie, der meinte, Deutschland habe nicht die Kräfte für einen solchen Entscheidungsschlag und müsse deshalb auf einen politischen Ausweg aus dem Krieg hoffen, scharf ab. ${ }^{47}$

Lediglich Vertrauen in das militärische Können der OHL hätte diesen Gegensatz mildern können, und dieses fehlte dem Kronprinzen. Am 2. März 1915 notierte Kronprinz Rupprecht nach einer Besprechung mit Falkenhayn:

"Sehr erschreckte mich seine Äußerung, dass es auf beiden Fronten zu einem Bewegungskriege nicht mehr kommen werde [...] Wer nichts wagt, der nichts gewinnt, sagt das Sprichwort, und wie soll der Krieg eine für uns entscheidende Wendung nehmen, wenn wir uns auf die strategische Defensive beschränken? Mir gefällt Falkenhayn immer weniger. Er ist voll hastiger Unruhe, ein Mann der kleinen Mittel, aber nicht der großen Ziele, geneigt, seine

46 Ebd., Eintrag vom 9.7.1916. Um Falkenhayn die Übernahme der Reichskanzlerschaft zu ermöglichen, sollen seine Schulden von 17 Millionen übernommen werden: »Ich hörte wohl schon früher, dass Falkenhayn, der seinerzeit sehr hoch gespielt haben soll, sehr verschuldet sei, aber 17 Millionen, das klingt dann doch gar hoch!«

47 Afflerbach, Falkenhayn (wie Anm. 43), S. 198-456, besonders S. 294-304. 
Maßnahmen von jenen des Gegners abhängig zu machen, anstatt diesem das Gesetz zu diktieren. $«^{48}$

In jeder Anordnung Falkenhayns glaubte er einen Fehler zu sehen, sei es bei dem tropfenweisen Einsatz seiner Armee in Flandern im Herbst 1914, der Organisation der Schlacht bei Arras im Mai 1915 oder der Vorbereitung auf die Schlacht an der Somme 1916. Vollkommen berechtigt war seine Kritik am Angriff auf Verdun 1916, den er von Anfang an für eine fatale Idee hielt. Er schrieb am 13. Januar 1916: "Galt es doch bisher gewiss nicht als ein Zeichen besonderer Feldherrnkunst, wenn man den Gegner gerade an seiner stärksten Stelle anpackte. « ${ }^{49}$ Falkenhayn sei, so glaubte der Prinz schon im Oktober 1914, der falsche Mann auf seinem Posten ${ }^{50}$ und müsse weg. Daran arbeitete der Kronprinz fast zwei Jahre, bis dieses Ziel schließlich erreicht war. Es wird in der Forschung zur deutschen Führung im Ersten Weltkrieg zu Recht sehr viel über die erbitterte Gegnerschaft zwischen Falkenhayn und Hindenburg/Ludendorff gesprochen. Diese war, ebenso wie die Intervention Bethmann Hollwegs, ein wichtiger Grund für Falkenhayns Ablösung. Aber eine Intervention Kronprinz Rupprechts im August 1916 spielte in diesem Zusammenhang ebenfalls eine wichtige Rolle. Der Prinz hatte in einem Brief an das Militärkabinett geschrieben, Falkenhayn besitze nicht mehr das Vertrauen der Armee. Es war dieser Brief, der schließlich dem Kaiser als Hauptgrund für die notwendige Entlassung Falkenhayns präsentiert wurde. $^{51}$

Auch nach dem Krieg sah Kronprinz Rupprecht in Falkenhayn nur einen militärischen Versager und wollte nicht akzeptieren, dass dieser die kräftemäßige Unterlegenheit der Mittelmächte und damit auch die Unmöglichkeit, einen militärischen Totalsieg erzwingen zu können, erkannt hatte. Falkenhayn hatte den Kronprinzen mit seiner Ansicht schockiert, es ginge darum, unter Verzicht auf entscheidungssuchende Operationen den Gegner zu ermatten und zu hoffen, dass

48 Rupprecht, In Treue fest (wie Anm. 7), Bd 1, S. 306 (Tagebucheintrag vom 2.3.1915).

49 Ebd., S. 414 (Tagebucheintrag vom 13.1.1916).

50 Ebd, S. 232-234 (Tagebucheintrag vom 27.10.1914).

51 Ebd., Bd 2, S. 48 (Tagebucheintrag vom 19.10.1916): »Den Anstoß zur Entlassung Falkenhayns habe ein Vortrag Lynckers gegeben, der darlegte, dass Falkenhayn nicht mehr das Vertrauen der Armee besitze. Ich merkte, worauf der Kaiser mit diesen Worten abzielte, und gestand, dass ich an Lyncker geschrieben, weil ich es bei dem Ernst der Lage für meine Pflicht hielt, dass Se[ine] Maj [estät] von zuständiger Seite die Wahrheit erführe.« Der Kaiser erklärte dann noch, Rupprecht habe »den richtigen Weg gewählt«. Siehe auch Rupprecht an Lerchenfeld, 3.7.1916, BayHStA, GHA, NL Rupprecht, Nr. 496, mit Klagen des Prinzen, Falkenhayn suche für seine eigenen Misserfolge immer einen Sündenbock, so gehe es nicht weiter, und Lerchenfeld solle dies dem Reichskanzler zeigen. 
dieser irgendwann einlenke..$^{52}$ Damit hatte der Generalstabschef jedoch, wie rückblickend deutlich wird, Deutschlands einzigen Ausweg, um aus diesem Krieg ohne Niederlage herauszukommen, beschrieben. Der Kronprinz war aber zu sehr von seiner Abneigung gegen Falkenhayn eingenommen, um nüchtern abzuwägen, ob dieser die strategische Gesamtlage nicht vielleicht richtig einschätzte. Stattdessen hielt er den Generalstabschef für kleinmütig und strebte in der ersten Kriegshälfte als Annexionist nicht nur für Deutschland, sondern auch für Bayern Gebietszuwachs an. Deutschland sollte Belgien behalten, Bayern das Elsass bekommen. ${ }^{53}$

In diesen Fragen - in dem Verhältnis zu Falkenhayn und auch der Stellung Bayers innerhalb des Reiches - wird beispielhaft deutlich, dass der Prinz sein Temperament und seine Abneigungen nicht ausreichend unter Kontrolle hatte, worin sich eine deutliche Beschränkung seines Könnens zeigt. Auch in seinen Verlautbarungen und Befehlen wählte er mitunter ebenso emotionale wie unglückliche Formulierungen, die in zumindest einem Fall stark an die »Hunnenrede« Wilhelms II. erinnern. ${ }^{54}$ So hatte er am 19. Oktober 1914 folgenden Tagesbefehl an die »Soldaten der 6. Armee« erlassen:

»Wir haben nun das Glück, auch die Engländer vor unserer Front zu haben, die Truppen dieses Volkes, dessen Neid seit Jahren an der Arbeit war, uns mit einem Ring von Feinden zu umgeben, um uns zu erdrosseln. Darum, wenn es gegen diesen Feind geht, übt Vergeltung für die feindselige Hinterlist, für so schwere Opfer. Zeigt ihnen, dass die Deutschen nicht so leicht aus der Weltgeschichte zu streichen sind. ${ }^{55}$

Im britischen Parlament wurde daraufhin angefragt, ob Rupprecht den Befehl gegeben habe, »kein Pardon zu geben«, und der Kronprinz selbst wurde in einer britischen Zeitung als »Oberhunne « bezeichnet. ${ }^{56}$ Nach dem Krieg stand er, unter anderem wegen dieses Befehls, auf der Liste auszuliefernder Kriegsverbrecher.

52 Rupprecht, In Treue fest (wie Anm. 7), Bd 1, S. 394 (Eintrag vom 13.10.1915) (»Ermattungsstrategie [...] Armutszeugnis«); S. 409 (Eintrag vom 25.10.1915).

53 Weiß, Kronprinz Rupprecht (wie Anm. 1), S. 130; dazu auch März, Das Haus Wittelsbach (wie Anm. 4), S. 384-395.

54 Dazu Bernd Sösemann, Die sog. Hunnenrede Wilhelms II. Textkritische und interpretatorische Bemerkungen zur Ansprache des Kaisers vom 27. Juli 1900 in Bremerhaven. In: Historische Zeitschrift, 222 (1976), S. 342-358.

55 Armeebefehl an die 6. Armee vom 19.10.1914. In: Rupprecht, In Treue fest (wie Anm. 7), Bd 3, S. 57 f. Siehe auch Sendtner, Rupprecht von Wittelsbach (wie Anm. 4), S. 313, und Weiß, Kronprinz Rupprecht (wie Anm. 1), S. 176.

56 Rupprecht, In Treue fest (wie Anm. 7), Bd 1, S. 361 (Tagebucheintrag vom 18.5.1915). 


\section{Kronprinz Rupprecht und die 3. OHL}

Im August 1916 wurde Falkenhayn durch Hindenburg und Ludendorff ersetzt. Praktisch gleichzeitig wurde Kronprinz Rupprecht die nach ihm benannte Heeresgruppe anvertraut, während er die Führung über die 6. Armee an Generaloberst Alexander Freiherr von Falkenhausen abgab. Die Einrichtung von Heeresgruppen war durch die schiere Größe des Millionenheeres und die Probleme, die sich an den Nahtstellen nebeneinander operierender Armeen ergaben, erzwungen und noch von Falkenhayn angeordnet worden..$^{57}$

Es ist eine Folge des fundamental gestörten Verhältnisses, das der Prinz zu Falkenhayn hatte, dass er erst nach dessen Abgang den Ernst der strategischen Lage erfasste. Offenbar hatte er vorher geglaubt, alle Misserfolge auf Falkenhayns vermeintliche Unfähigkeit zurückführen zu können. Als Hindenburg und Ludendorff $^{58}$ dann die Strategie Sieg oder Untergang verfochten, wechselte Rupprecht sehr rasch in das Lager der Skeptiker über, die das Ende der deutschen Leistungsfähigkeit immer deutlicher kommen sahen, und vertrat damit nun ähnliche strategische Grundideen wie Falkenhayn.

Sein persönliches Verhältnis zu Hindenburg und Ludendorff war zunächst bedeutend besser als das zu Falkenhayn. Kronprinz Rupprecht mochte Hindenburg, er schätzte die präzise Art Ludendorffs, der anders als Falkenhayn die Dinge direkt und offen ansprach, und hielt ihn für einen guten General. ${ }^{59}$ Doch bald schon hatte der Prinz auch an Ludendorff, dem strategischen Kopf des Feldherrnduos, manches auszusetzen. Seine Kritik erinnert an die Klagen der Generäle des Zweiten Weltkriegs über die ständigen Einmischungen Hitlers. Der Prinz beklagte vor allem im Jahre 1918 die stete und zunehmende Einmischung Ludendorffs in seinen Verantwortungsbereich, dessen Herumtelefonieren mit seinem Stab und unterstellten Einheiten, die er, unter Übergehung Rupprechts, einfach hin- und herschob. ${ }^{60}$ Er kritisierte, dass Ludendorff sich im Politischen verzettele, für das er keine Begabung besitze, und darob seine militärischen Aufgaben vernachlässige. Hinzu gesellte sich ein noch weit gravierenderer Gegensatz, der mit einem Zitat aus Ludendorffs Kriegserinnerungen verdeutlicht werden soll:

57 Dazu sehr kurz: Der Weltkrieg 1914-1918. Die militärischen Operationen zu Lande, 14 Bde; 2 Sonderbde. Hrsg. vom Reichsarchiv/Forschungsanstalt für Kriegs- und Heeresgeschichte/ Bundesarchiv, Berlin/Koblenz, Berlin 1925-1956, Bd 10, S. 422 f.

58 Nebelin, Ludendorff (wie Anm. 12), Pyta, Hindenburg (wie Anm. 12).

59 Weiß, Kronprinz Rupprecht (wie Anm. 1), S. 117.

60 Rupprecht, In Treue fest (wie Anm. 7), Bd 2, S. 435 (Tagebucheintrag vom 9.8.1918), S. 443 (Eintrag vom 9.9.1918). 


\begin{abstract}
»Ebenso wie der deutsche Kronprinz war der bayerische einer Beendigung des Krieges ohne jeden Gewinn zugetan, aber ob die Entente darauf eingehen würde, das wusste auch er nicht. $\ll^{61}$
\end{abstract}

Ludendorff pflegte in den zahllosen Besprechungen zur Strategie und in den Auseinandersetzungen mit andersdenkenden Politikern, Diplomaten und Militärs seine Gegenspieler ziemlich erfolgreich mit dem Argument mundtot zu machen, dass der Gegner in seinem Sieges- und Vernichtungswillen Deutschland keine Wahl lasse und deshalb die Parole für Deutschland, für Heer und Heimat, nur Sieg oder Untergang lauten könne. ${ }^{62}$ Prinz Rupprecht sah die Einseitigkeit dieser Haltung und schrieb: »Ludendorff ist ein ausgesprochener Willensmensch, aber der Wille allein genügt nicht, wenn ein nüchterner Verstand ihn nicht zügelt. « ${ }^{63}$ Ludendorff wiederum vermisste bei Rupprecht das, was er für die Entschlossenheit und den Siegeswillen des echten Soldaten hielt.

Kronprinz Rupprecht hatte an Falkenhayn einst bemängelt, dass er den großen Wurf nicht gewagt habe. Doch nun glaubte auch er, dass Deutschland nicht mehr die Kraft für einen Entscheidungsschlag habe. ${ }^{64}$ Der große Wendepunkt war für ihn die Sommeschlacht 1916 gewesen. ${ }^{65}$ Dieser britische und französische Angriff, der sich über Monate hinzog, war zwar von den Deutschen abgeschmettert worden - und zwar von der im August 1916 gebildeten Heeresgruppe Kronprinz Rupprecht. Doch der große deutsche Abwehrerfolg wurde dadurch überschattet, dass sich während der Schlacht die geradezu erdrückende materielle Überlegenheit der Westmächte, besonders bei Artillerie und Munition, manifestiert hatte. Der Kronprinz war nach Ansicht seiner gesamten Umgebung sehr nachdenklich und pessimistisch geworden ${ }^{66}$ und begann zunehmend die Meinung zu vertreten, weder das Deutsche Reich noch das verbündete Österreich-

61 Ludendorff, Meine Kriegserinnerungen (wie Anm. 16), S. 216.

62 Dazu Holger Afflerbach, »... eine Internationale der Kriegsverschärfung und der Kriegsverlängerung ...«War Aims and the chances for a compromise peace during the First World War. In: The Purpose of the First World War. War Aims and Military Strategies. Ed. by Holger Afflerbach, München 2015 (= Schriften des Historischen Kollegs, 91), S. 237-254.

63 Rupprecht, In Treue fest (wie Anm. 7), Bd 2, S. 320 (Tagebucheintrag vom 19.1.1918); siehe auch Sendtner, Rupprecht von Wittelsbach (wie Anm. 4), S. 294.

64 Sendtner, Rupprecht von Wittelsbach (wie Anm. 4), S. 284.

65 BayHStA, GHA, NL Rupprecht, Nr. 708, Kriegstagebuch, Eintrag vom 8.8.1918: Der deutsche Kronprinz sei gedämpft, auch die OHL wolle Frieden. Der deutsche Kronprinz habe gesagt, dass Rupprecht seit der Somme einen »gedrückten Eindruck« mache. »Nun sieht er ein, dass ich die Dinge doch nicht unrecht beurteilte."

66 Sendtner, Rupprecht von Wittelsbach (wie Anm. 4), S. 280, zitiert Loßberg. 
Ungarn könne noch lange weiterkämpfen. ${ }^{67}$ Hier öffnete sich zwischen Kronprinz Rupprecht und Ludendorff eine Kluft, die sich auch dann nicht schloss, als Ludendorff am 26. Oktober 1918 entlassen wurde - was Rupprecht mit einem erleichterten »Gott sei Dank! « in seinem Tagebuch kommentierte. ${ }^{68}$

Doch zuvor hatte der Kronprinz seinen gesamten politischen und militärischen Einfluss dafür eingesetzt, die Katastrophe, die er seit Ende 1916 kommen sah, aufzuhalten. Doch war sein Einfluss auf die großen militärischen und politischen Entscheidungen begrenzt. Auf der politischen Ebene fehlte ihm die Rückendeckung, sodass seine Interventionen nicht beachtet wurden. Auch in seinem Vater fand er keinen Rückhalt. Das Verhältnis zu ihm war miserabel, denn Ludwig III. beurteilte die Lage sehr viel optimistischer und verfolgte für Bayern ähnliche expansionistische Pläne wie auch Rupprecht in den ersten Jahren des Krieges. ${ }^{69}$ Doch inzwischen war der Sohn, anders als der Vater, zur Vernunft gekommen. Ludwig III. war allerdings kein Einzelfall - bis Kriegsende hatte sich ein rückblickend bizarr anmutender Imperialismus in den Regierungen der deutschen Einzelstaaten verbreitet. ${ }^{70}$ Der fehlende Rückhalt bei seinem Vater machte es Prinz Rupprecht wiederum unmöglich, erfolgreich auf den Kaiser einwirken zu können. Die deutschen und bayerischen Politiker unterstützten ihn ebenfalls nicht. Hier ist vor allem Georg Graf Hertling zu nennen, der im November 1917 Reichskanzler geworden und zuvor bayerischer Ministerpräsident gewesen war.

Auch auf militärischer Ebene war sein Einfluss begrenzt. Hier vermochte er der Obersten Heeresleitung, also Hindenburg und Ludendorff, lediglich Vorschläge zu machen, die aber von diesen leicht verworfen werden konnten. Der Prinz war zwar Befehlshaber einer Armee und dann sogar einer Heeresgruppe, war dies aber geworden, weil er bayerischer Thronfolger war, und nicht etwa aufgrund überragender militärischer Begabung. Wahrscheinlich hatte er als

67 Siehe dazu auch Georg Alexander von Müller, Regierte der Kaiser? Kriegstagebücher, Aufzeichnungen und Briefe des Chefs des Marine-Kabinetts Admiral Georg Alexander von Müller 1914-1918. Hrsg. von Walter Görlitz, Göttingen 1959, S. 314 (Tagebucheintrag vom 20.8.1917): »Der Kronprinz von Bayern sehr pessimistisch gestimmt [...] Er hält eine Fortsetzung des Krieges über den Winter hinaus für unmöglich [...] Lyncker veranlasst, dass beim Frühstück der General Sixt v[on] Arnim dem Kaiser wenigstens sagt, dass uns die Juli- und Augustkämpfe bei der 4. Armee 84000 Mann Verluste gekostet haben, was aber anscheinend keinen großen Eindruck auf den Kaiser gemacht hat.«

68 BayHStA, GHA, NL Rupprecht, Nr. 708, Kriegstagebuch, Eintrag vom 25.10.1918.

69 Rupprecht an Hertling, 1.6.1918. In: Rupprecht, In Treue fest (wie Anm. 7), Bd 3, S. 24: »Ich selbst vertrat einst den Gedanken der Angliederung Belgiens an das Deutsche Reich in irgendeiner Form."

70 Dazu Karl Heinz Janßen, Macht und Verblendung. Kriegszielpolitik der deutschen Bundesstaaten 1914/18, Göttingen 1963. 
Thronfolger weder in der Politik noch in der Armee eine wirklich starke Position. Die Vorgänge in der Ära Falkenhayn hatten gezeigt, dass der Prinz im Alleingang machtlos war und seine Intervention nur dann durchsetzen konnte, wenn sie mit der anderer Entscheidungsträger aus Politik und Militär einherging.

Rupprecht schloss sich in seiner Opposition mit jenen zusammen, die seine Ansichten teilten und sich in einem ähnlichen Dilemma der Machtlosigkeit befanden - wobei Macht hier im Sinne der klassischen Definition Max Webers als »Chance, innerhalb einer sozialen Beziehung den eigenen Willen auch gegen Widerstreben durchzusetzen, gleichviel worauf diese Chance beruht», definiert werden soll. ${ }^{71} \mathrm{Zu}$ denen, die sich durch die Einsicht in die Probleme und gleichzeitig durch fehlende Durchsetzungsmöglichkeiten vereint sahen, gehörten in diesem Krieg der Prinzen besonders die Thronfolger der Einzelstaaten. Neben Rupprecht sind hier Kronprinz Wilhelm von Preußen und Prinz Max von Baden zu erwähnen. Die drei Prinzen teilten ab 1916 die Sorge, dass dieser Krieg mit einer schweren deutschen Niederlage enden könne, wenn das Steuer der deutschen Politik nicht bald und ganz entschieden herumgerissen werden sollte. Sie sprachen sich ab, intervenierten gemeinsam und suchten die Dinge in ihrem Sinn zu beeinflussen. ${ }^{72}$

Kronprinz Rupprecht versuchte auf der militärischen und auf der politischen Ebene seine Ansichten durchzusetzen. Dabei hatte er auch einige Erfolge. Um die Jahreswende 1916/17 bewegten Rupprecht und sein Stabschef von Kuhl zuerst die widerstrebenden Stäbe der unterstellten Armeen und dann die OHL zum Rückzug an der Westfront auf kürzere Linien und zur Preisgabe von Gelände. ${ }^{73}$ Dieser

71 Max Weber, Wirtschaft und Gesellschaft. Grundriß der verstehenden Soziologie, 1. Halbbd, Tübingen 1921/1980, S. 28.

72 Dazu jetzt Lothar Machtan, Prinz Max von Baden. Der letzte Kanzler des Kaisers. Eine Biographie, Berlin 2013; siehe auch Lothar Machtan, Autobiographie als geschichtspolitische Waffe. Die Memoiren des letzten kaiserlichen Kanzlers Max von Baden. In: Vierteljahrshefte für Zeitgeschichte, 4/2013, S. 481-512.

73 Bay HstA, GHA, NL Rupprecht, Nr. 724, Kuhl an Rupprecht, 31.5.1921. Aus diesem Brief wird deutlich, in welcher Weise der Entscheidungsfindungsprozess in der deutschen Armee auf Austausch von Meinungen, auf Überzeugsarbeit und dann erst dem Entschluss basierte. Er zeigt auch, wie der Oberbefehlshaber und sein Stabschef gemeinsam agierten und ihre Ansichten gegen Widerstand von oben und unten durchsetzen konnten. Kuhl schrieb: „Der Vorschlag, in die Siegfriedstellung zurückzugehen, ist nicht vom General Fuchs ausgegangen. Ich war nach vielen Bedenken zur Überzeugung gekommen, dass dieser Rückzug nötig sei und versammelte die Armeechefs zu einer Besprechung. Alle erklärten sich dagegen, insbesondere sprach sich Loßberg aufs schärfste dagegen aus. Ich wandte mich darauf an befreundete Frontoffiziere, insbesondere an meinen alten Freund Fuchs, um dessen Ansicht zu hören. Fuchs stimmte meinem Vorschlag durchaus zu und kam zu diesem Zwecke auf meine Bitte nach Cambrai. Daraufhin trug ich Eurer Königlichen Hoheit die Frage zur Entscheidung vor und betonte die unbedingte Notwendigkeit 
Rückzug im März 1917 auf die Siegfriedlinie störte die gegnerischen Angriffsvorbereitungen beträchtlich und ließ diese teilweise zum Luftstoß werden. Unternehmen »Alberich«, so der Deckname des Rückzugs, war ein militärischer Erfolg, wenn auch die Maßnahme wegen der radikalen Verwüstung der zurückzulassenden Gebiete - Häuser und Kanäle wurden gesprengt, Gleise abgebaut, Chausseebäume gefällt, die Einwohner ausgesiedelt - umstritten war und bei den Franzosen ungeheure Erbitterung auslöste. Kronprinz Rupprecht hatte unter Rücktrittsdrohung versucht, die planmäßige Verwüstung des zurückgelassenen Gebietes und die Aussiedlung der über 140000 Bewohner zu verhindern. Allerdings konnte er sich nicht durchsetzen. Gleichzeitig wurde ihm deutlich gemacht, welche politischen Auswirkungen sein Rücktritt haben würde. Da Rupprecht nicht bereit war, seine Position aufzugeben, lenkte er ein und blieb im Amt, ${ }^{74}$ was wohl ein Fehler war. Noch ein Jahr später machte er die Verwüstungen durch »Alberich « für die Verrohung und den »Plünderungstrieb « unter den deutschen Soldaten verantwortlich. ${ }^{75}$

Auch im Politischen blieben seien Vorstöße weitgehend erfolglos. Der Prinz wandte sich 1918 wiederholt an seinen Vater und beschrieb diesem drastisch die Situation; er machte klar, dass Deutschland den Krieg verlieren werde, wenn es so weitergehen würde, und forderte ihn als König des zweitgrößten Bundesstaates zum Handeln auf, etwa durch eine Intervention beim Kaiser. Rupprecht suchte zudem auf Georg von Hertling einzuwirken. Doch auch Hertling vertraute mehr auf die "genialen Führer«, wie er Hindenburg und Ludendorff im Reichstag nannte, ${ }^{76}$ und auf deren Fähigkeit, den Sieg zu erstreiten, als dass er die Warnungen des Prinzen vor einer drohenden Niederlage ernst genommen hätte.

des Rückzuges. Eure Königliche Hoheit stimmten zu. Aber die OHL lehnte unseren Antrag ab. Ludendorff ließ sich in vielen Gesprächen erst sehr langsam umstimmen. Eure Königliche Hoheit haben aber die Entscheidung zu dem Antrag an die OHL getroffen und haben die Durchführung trotz der Abneigung der OHL durchgesetzt." Im entsprechenden Band der offiziellen Geschichte des Weltkrieges - Der Weltkrieg 1914-1918 (wie Anm. 57), Bd 12 - findet sich auf S. 119-146 eine Schilderung des »Alberich«-Rückzugs, nichts jedoch über die hier von Kuhl erwähnten Diskussionen.

$74 \mathrm{Zu}$ »Alberich« siehe Michael Geyer, Rückzug und Zerstörung 1917. In: Die Deutschen an der Somme 1914-1918. Krieg, Besatzung, Verbrannte Erde. Hrsg. von Gerhard Hirschfeld, Gerd Krumeich und Irina Renz, Essen 2006, S. 163-202; März, Das Haus Wittelsbach (wie Anm. 4), S. 336. Zu Rupprechts Opposition und Rücktrittsdrohung, auch der Verweigerung des Rücktritts: Weiß, Kronprinz Rupprecht (wie Anm. 1), S. 119.

75 BayHStA, GHA, NL Rupprecht, Nr. 708, Kriegstagebuch, Eintrag vom 6.5.1918.

76 Hertling im Reichtstag, 25.2.1918 <www.reichstagsprotokolle.de/Blatt_k13_bsb00003407_ 00281.html> (letzter Zugriff 12.7.2015). 
Einen weiteren Vorstoß unternahm Rupprecht im Jahre 1918, indem er den badischen Thronfolger, Prinz Max von Baden, der sich mehrfach für die Politik der Verständigung ausgesprochen hatte, unterstützte und geradezu anfeuerte in seinem Ehrgeiz, Reichskanzler zu werden. Wie wir aufgrund der Forschungen von Lothar Machtan wissen, waren Max von Baden viele dieser Pläne von seinem Berater Kurt Hahn eingeredet worden, ohne dass er selbst von ihnen hundertprozentig überzeugt war. Außerdem fehlten ihm elementare persönliche Voraussetzungen, um ein energischer Kanzler werden zu können; aber immerhin trat Max von Baden als jemand auf, der das Gespräch mit dem Gegner suchte, und Rupprecht unterstützte ihn darin. ${ }^{77}$ Es scheint, dass Rupprecht die für einen erfolgreichen Friedensstifter erforderlichen, schmerzlichen Schritte tatsächlich gebilligt hätte. ${ }^{78} \mathrm{Er}$, der Annexionist der ersten Kriegshälfte, wollte Belgien nun preisgeben und hatte mit Kronprinz Wilhelm von Preußen darüber hinaus die Abgabe von französischsprachigen Teilen Elsass-Lothringens an Frankreich erwogen $^{79}$ - ja, sogar an die Abtretung der gesamten Reichslande gedacht. ${ }^{80}$ Die beiden Kronprinzen bewiesen hier eine Einsichtigkeit, die über diejenige der Politiker der im Reichstag vertretenen Parteien und über die ihrer Väter weit hinausging. Sie forderten im Herbst 1916 auch ein Sonderfriedensangebot an Russland und hielten die Polenproklamation der Mittelmächte für einen schweren Fehler, da sie eine Einigung mit Russland unmöglich machte. ${ }^{81}$

Den Höhepunkt erreichten Rupprechts Anstrengungen im Vorfeld der Planungen für die große deutsche Frühjahrsoffensive 1918 an der Westfront. Die Amerikaner waren im April 1917 in den Krieg eingetreten, als Reaktion auf die Erklärung des uneingeschränkten U-Boot-Krieges durch das Deutsche Reich am 1. Februar 1917. Der Prinz hatte sich mit dieser Frage weniger intensiv auseinandergesetzt als mit vielen anderen strategischen und operativen Problemen, die uns heute weniger wichtig erscheinen mögen. Er hatte diesen deutschen Schritt zunächst ambivalent beurteilt, schließlich aber als einzige Möglichkeit, eine Entscheidung militärisch zu erzwingen, befürwortet. ${ }^{82}$ Im Frühjahr 1918 erkannte Rupprecht, dass der U-Boot-Krieg Deutschland um den Sieg gebracht hatte. Am 9. Mai 1918 schrieb er:

77 Dazu Machtan, Max von Baden (wie Anm. 72), besonders S. 355-361 und S. 362-366.

78 Rupprecht, In Treue fest (wie Anm. 7), Bd 2, S. 91 (Eintrag vom 27.1.1917).

79 Müller, Regierte der Kaiser (wie Anm. 67), 10.9.1917.

80 BayHStA, GHA, NL Rupprecht, Nr. 705, Kriegstagebuch, Eintrag vom 12.4.1917: »falls wir die Reichslande überhaupt behalten können.«

81 Rupprecht, In Treue fest (wie Anm. 7), Bd 2, S. 50 (Eintrag vom 22.10.1916); S. 60 (Eintrag vom 5.11.1916); S. 62 (7.11.1916); siehe auch März, Das Haus Wittelsbach (wie Anm. 4), S. 301.

82 Rupprecht, In Treue fest (wie Anm. 7), Bd 2, S. 99 (Eintrag vom 15.2.1917). 
»Hätten wir nicht den unbeschränkten U.B. Krieg begonnen, hätten wir wohl kaum den Krieg mit Amerika bekommen und wäre damit der Krieg mit den Westmächten jetzt wohl schon für uns siegreich beendet; diese Überzeugung drängt sich mir jetzt nachträglich auf. Der Admiralstab hat eine schwere Schuld auf sich geladen mit seinen viel zu weit gehenden Versprechungen hinsichtlich der Wirksamkeit des UB Krieges. «83

Die U-Boote konnten, anders als der Admiralstab versprochen hatte, weder Großbritannien aus dem Krieg zwingen noch verhindern, dass die USA große Truppenkontingente nach Europa brachten.

Anfang 1918 wollte Ludendorff den Krieg nach dem russischen Ausscheiden durch eine große Offensive im Westen siegreich beenden, bevor sich die Intervention der USA massiv auswirken konnte. ${ }^{84}$ Dieser Versuch, den Krieg durch einen großen Schlag im Westen zu entscheiden, war in der Führungschicht weitgehend unumstritten. Es gab, nach einem Wort von Dieter Storz, keine »Defensivpartei«, die den Krieg durch die strategische Defensive und Verhandlungen zu Ende bringen wollte. ${ }^{85}$ Kronprinz Rupprecht stand, zumindest innerhalb der politischen und militärischen Führung, praktisch allein, als er eine andere Strategie favorisierte. Er wollte die zeitweise deutsche Überlegenheit an der Westfront als Druckmittel nutzen, um mit dem Gegner in Verhandlungen zu treten; dies in der Hoffnung, eine Offensive möge gar nicht mehr notwendig werden. Er sah in der Offensive ein letztes Mittel; sollte sie scheitern, wäre der Krieg für Deutschland unrettbar verloren.

Kronprinz Rupprecht hat diesen Plan Anfang 1918 auch offensiv verfolgt. Aus der Rückschau ist unstrittig, dass der Prinz damit eine sehr viel realistischere Strategie vertrat als Ludendorff. Er hatte die Grenzen der deutschen militärischen Leistungsfähigkeit klar erkannt und war bereit, die deutschen Ziele zu begrenzen, anstatt das Unmögliche zu versuchen und nach dem militärischen Sieg zu greifen. Doch konnte sich der Prinz gegen den Generalstab nicht durchsetzen.

Rupprecht und seine Heeresgruppe nahmen an einer Offensive teil, der er mit unverhohlen großer Skepsis gegenüberstand. Er bemühte sich trotzdem nach

83 BayHStA, GHA, NL Rupprecht, Nr. 708, Kriegstagebuch, Eintrag vom 9.5.1918; vgl. Rupprecht, In Treue fest (wie Anm. 7), Bd 2, S. 396, ohne den letzten Satz zitiert.

84 Dazu Dieter Storz, »Aber was hätte anders geschehen sollen?« Die deutschen Offensiven an der Westfront 1918«. In: Kriegsende 1918. Ereignis, Wirkung, Nachwirkung. Im Auftrag des Militärgeschichtlichen Forschungsamtes hrsg. von Jörg Duppler und Gerhard P. Groß, München 1999 (= Beiträge zur Militärgeschichte, 53), S. 51-95; David Stevenson, With Our Backs to the Wall: Victory and Defeat in 1918, London 2011, der sich bei der Erörterung der deutschen Offensive 1918 und ihrer Chancen auf Storz stützt.

85 Storz, »Aber was hätte anders geschehen sollen?« (wie Anm. 84), S. 100. 
Kräften, dem Angriff zum Erfolg zu verhelfen. Sein Heeresgruppenstab war von Ludendorff in die Planungen für die Westoffensive 1918 eingebunden worden. Rupprecht und sein Stabschef, Generalleutnant von Kuhl, favorisierten einen Angriff auf die britischen Stellungen, der im Erfolgsfall die Kanalhäfen in deutsche Hand gebracht hätte. ${ }^{86}$ Dieser Angriff wäre nicht kriegsentscheidend gewesen, hätte aber im Erfolgsfall einen großen strategischen Vorteil gebracht. Ludendorff wollte hingegen an der Nahtstelle zwischen britischen und französischen Truppen angreifen, da er hier taktisch günstigere Bedingungen für einen Angriffserfolg sah. - Dies stimmt zweifelsohne - aber was sollte dann geschehen? Dieser Angriff würde im Nirgendwo enden; für eine entscheidende Ausnutzung, etwa der Abdrängung der Engländer ins Meer, reichten die Kräfte nicht aus. Das deutsche Westheer war, trotz Verstärkung von der Ostfront, nicht stark genug für einen solchen Angriff; auch fehlte es an Beweglichkeit, an Lastwagen und an Pferden. ${ }^{87}$

Beide Angriffsvorschläge hatten ihre Risiken. Es gab keine Garantie, dass der begrenzte Angriff, den Rupprecht und Kuhl bevorzugten, nicht ebenso scheitern würde wie der britische im Vorjahr in Flandern. Außerdem hätte in dem von ihnen vorgeschlagenen Gebiet erst im Frühjahr angegriffen werden können, da gewartet werden musste, bis das Gelände hinreichend trocken ist. Doch Ludendorff fühlte sich von der drohenden massiven Intervention der Amerikaner an der Westfront unter Zeitdruck gesetzt. Daher fiel es ihm leicht, seinen eigenen Angriffsplan zu begründen und durchzusetzen. Ludendorff argumentierte außerdem, dass der taktische Erfolg essenziell sei und sich der strategische aus ihm ergeben müsse. Kuhl erinnerte sich später:

»Ludendorff warf mir damals immer vor, die Heeresgruppe wolle immer operieren. Man dürfe nur taktisch denken. Man müsse angreifen und dann sehen, was daraus wird. In Russland habe er es immer so gemacht. $«^{88}$

Nach Angriffsbeginn im März 1918 sah es für einige Tage so aus, als habe Ludendorff Recht behalten. Seine Offensive war zunächst so erfolgreich, dass selbst der skeptische Kronprinz glaubte, der Sieg sei erstritten. (»Der Sieg ist unser! Wer hätte vor 24 Stunden einen derartigen Erfolg sich verhofft! «89) Ludendorffs weitere Dispositionen zeigten ihm aber sehr schnell, dass der Angriff ein taktischer Erfolg, aber ein strategischer Fehlschlag war, und schon am 27. März meinte

86 Der Weltkrieg 1914-1918 (wie Anm. 57), Bd 14, S. 55-62.

87 Dazu Storz, »Aber was hätte anders geschehen sollen? (wie Anm. 84), und Stevenson, With Our Backs to the Wall (wie Anm. 84), S. 30-111.

88 BayHStA, GHA, NL Rupprecht, Nr. 724: Kuhl an Kronprinz Ruprecht, 2.9.1920.

89 Rupprecht, In Treue fest (wie Anm. 7), Bd 2, S. 350 (Eintrag vom 21.3.1918). 
er: »Nun haben wir den Krieg verloren. ${ }^{90}$ Die Kritik Rupprechts wurde nun massiv; Ludendorffs weitere Aktionen schienen ihm strategisch sinnlos und vor jedem neuen Schlag mahnte er, Deutschland solle lieber Verhandlungen suchen, solange es noch eine gewisse militärische Stärke habe. Allerdings glaubte der Prinz, darin zu optimistisch, dass der Gegner überhaupt verhandlungsbereit war. ${ }^{91}$ Über Ludendorff äußerte er sich zunehmend abwertend, was in seinem Urteil vom 25. Oktober 1918 gipfelte: »Ludendorff muss fort, und er verdient auch nichts besseres, denn er hat die heurigen Offensiven erbärmlich schlecht geleitet, und sollte Hindenburg mit ihm gehen, der mir menschlich ja sympathisch ist, wäre es in militärischer Hinsicht auch kein Unglück, in politischer aber ein Glück [...] Wir müssen ungesäumt Frieden machen, sonst haben wir das Allerschlimmste zu erwarten. « ${ }^{92}$

Seine Mahnungen, auch an seinen Vater, wurden im Sommer 1918 immer dringender. Man müsse Frieden schließen, auch wenn es Opfer koste; wenig später schrieb er gar von "großen Opfern« und kritisierte, dass jeder, »der ein Bedenken äußert, [...] als ein Flaumacher und Pessimist, als ein Schwächling und minderwertiger Mensch « angesehen werde..$^{93}$ Doch nichts geschah, während der Gegner zum Gegenangriff überging und die deutschen Armeen an der Westfront sich seit Juli 1918 in die immer aussichtslosere Verteidigung gegen einen weit überlegenen Feind gedrängt sahen. Ab August 1918 wurde die Lage ausgesprochen kritisch, und Ende September 1918 erwartete Rupprecht einen feindlichen Durchbruch täglich, ja stündlich. Am 29. September 1918 - den Briten war der Einbruch in die Hindenburgstellung gelungen - schrieb er: „Wir müssen unbedingt Frieden schließen, es ist nichts mehr zu machen! «94 Ähnlich urteilten auch andere Heerführer der Westfront. ${ }^{95}$ Schließlich zog Ludendorff die Konsequenz und verlangte von der deutschen Regierung einen sofortigen Waffenstillstand, um dem Heer eine vernichtende Niederlage zu ersparen.

90 Ebd., S. 359 (Eintrag vom 27.3.1918).

91 Bay HStA, GHA, NL Rupprecht, Nr. 704, Tagebucheintrag, 20.6.1918: »Und schon aus diesem Grunde wünsche ich von Herzen, dass der Krieg nicht mehr allzu lange währen möchte, allein ich fürchte, er wird bis zu unserer völligen Erschöpfung fortgesetzt werden, da man sich deutscherseits nicht rechtzeitig zu Zugeständnissen versteht.«

92 BayHStA, GHA, NL Rupprecht, Nr. 650, Abschrift Rupprecht an Max von Baden, 25.10.1918. Siehe dazu auch Machtan, Max von Baden (wie Anm. 72), S. 422.

93 Rupprecht an seinen Vater, 25.7.1918 (»unter Opfern«), 4.9.1918 (»selbst unter großen Opfern«), 30.9.1918 (»Flaumacher«). Rupprecht, In Treue fest (wie Anm. 7), Bd 3, S. 24-27.

94 BayHStA, GHA, NL Rupprecht, Nr. 708, Kriegstagebuch, Eintrag vom 29.9.1918; großteils zitiert in: Rupprecht, In Treue fest (wie Anm. 7), Bd 2, S. 452.

95 Siehe beispielsweise die Haltung Lossbergs, des Chefs der Heeresgruppe Boehn, bei Holger Afflerbach, Die Kunst der Niederlage. Eine Geschichte der Kapitulation, München 2013, S. $204 \mathrm{f}$. 
Der Kronprinz hatte diesen Zusammenbruch seit über einem Jahr kommen sehen. Er war niedergedrückt und litt unter Schlaflosigkeit, Herz- und Kopfschmerzen. ${ }^{96}$ Auch als Privatmann hatte sich Rupprecht ein Kriegsende seit Langem ersehnt, da er, der vor dem Krieg Witwer geworden war und auch mehrere Kinder verloren hatte, darunter einen Sohn, der im August 1914 an Kinderlähmung verstorben war, eine neue Familie gründen wollte und befürchtete, bald $\mathrm{zu}$ alt dafür zu sein. ${ }^{97}$ Er empfand nach Aussage seines Tagebuches eine Abneigung gegen sinnlose Gewaltmaßnahmen, und zwar im Großen wie im Kleinen. Luftangriffe gegen England oder die Beschießung von Paris mit einem Ferngeschütz hielt er für sinnlose Provokationen, die nur Repressalien nach sich zögen, ohne den Gegner zum Einlenken zu bringen. Er beklagte auch die »furchtbaren JudenPogrome in Turkestan. ${ }^{98}$ Er bewies zudem Menschlichkeit im Kleinen und wandelte beispielsweise das Todesurteil für ein Mädchen, das vorgab, eine Spionin zu sein und als Märtyrerin für ihr Land sterben zu wollen, in eine Gefängnisstrafe um. ${ }^{99}$

Kronprinz Rupprecht hatte seine Rolle als Armee- und Heeresgruppenkommandeur an der Westfront als "undankbare Aufgabe « ${ }^{100}$ empfunden, da er und sein Stab hier in einen statischen und stumpfsinnigen Stellungskrieg eingebunden waren, in dem sie nur begrenzten Spielraum hatten und sehr lange auf defensive Aufgaben beschränkt waren. Der Kronprinz wurde zwar von der deutschen Kriegspropaganda zum »Wächter an der flandrischen Front « stilisiert, ${ }^{101}$ hätte aber eine andere, militärisch kreativere Aufgabe bevorzugt. Seine Ideen für alternative Strategien hatte er nicht durchsetzen können, obwohl er sie entschlossen vertreten und bei Ludendorff, Hertling, dem Kaiser und dessen Ratgebern seine Ansichten offen zur Sprache gebracht hatte. Dass seine Warnungen in der zweiten Kriegshälfte nicht berücksichtigt wurden, sprach aber weniger gegen den Prinzen, als vielmehr gegen jene, die sie nicht beachteten, wie den Kaiser, Reichskanzler Hertling, Hindenburg und Ludendorff oder auch seinen Vater, König Ludwig III. Rupprecht war nicht frei von Fehleinschätzungen, aber er überragte sie deutlich an Einsicht und auch an Konsequenz, und seine Analysen der strategischen Lage in der zweiten Kriegshälfte erwiesen sich als fundiert und realistisch. Erst im Oktober 1918 kam es zum Kurswechsel in der deutschen Politik, als Max

96 BayHStA, GHA, NL Rupprecht, Nr. 708, Kriegstagebuch, Eintrag vom 2.10.1918.

97 Ebd., Eintrag, vom 20.6.1918.

98 Ebd., Nr. 707, Kriegstagebuch, Eintrag vom 6.4.1918.

99 Ebd., Nr. 701, Kriegstagebuch, Eintrag vom 27.2.1915.

100 März, Das Haus Wittelsbach (wie Anm. 4), S. 328; Sendtner, Rupprecht von Wittelsbach (wie Anm. 4), S. 279.

101 März, Das Haus Wittelsbach (wie Anm. 4), S. 337. 
von Baden zum Reichskanzler ernannt wurde. Mit Max teilte Rupprecht die Einschätzung, dass die deutsche Politik schwere Fehler in ihrer Diplomatie und in der Außenwirkung begangen hatte.

\section{Kronprinz Rupprecht und die Niederlage und Revolution 1918}

Doch die Wende kam zu spät. Wann sah Kronprinz Rupprecht, dass nicht nur der Krieg verlorenging, sondern dass die Niederlage ihn auch die Thronanwartschaft kosten und die 738-jährige Herrschaft der Wittelsbacher in Bayern beenden würde? Diese Einsicht kam, trotz aller Skepsis, sehr spät. Noch im Oktober 1918 hatte er hässliche Auseinandersetzungen mit seinem Vater um seinen Münchner Wohnsitz. Ludwig III. wollte ihn, so glaubte Rupprecht, aus »reiner Chicane und Rachsucht« zu einem unvorteilhaften Umzug in das renovierungsbedürftige Palais Leuchtenberg zwingen. Dies sieht nicht danach aus, als glaubten Vater oder Sohn an das baldige Ende ihrer Herrschaft. Gleichzeitig hatte der Prinz sich bereits darum bemüht, nach Bayern versetzt zu werden, um dort im Fall des österreichischen Zusammenbruchs und eines italienischen Vorstoßes die Grenzverteidigung organisieren zu können. Dies war von Wilhelm II. abgelehnt worden. ${ }^{102}$ Kronprinz Rupprecht, der selbst in dieser Lage auf den Vorteil Bayerns bedacht war, stellte sogar schon, wie oben erwähnt, Überlegungen an, ob nicht nach einem Zerfall der Habsburgermonarchie Teile von Deutsch-Österreich an Bayern angeschlossen werden sollten.

Rupprecht hatte die bayerische Monarchie für sehr stabil gehalten. Doch auch sie geriet in den Strudel der Niederlage. Diese allein hätte nicht automatisch den Zusammenbruch der deutschen Monarchien nach sich ziehen müssen, wie das bulgarische Beispiel zeigt. Ferdinand von Bulgarien hatte im Moment der Niederlage die logische Konsequenz aus dem verlorenen Weltkrieg gezogen und zugunsten seines Sohnes Boris rechtzeitig und aus freien Stücken abgedankt; die bulgarische Monarchie überlebte den Krieg. Doch Wilhelm II., der von der Regierung des Prinzen Max von Baden und schließlich von weiten Teilen der Bevölkerung und der Armee zum Rücktritt gedrängt wurde, weigerte sich hartnäckig, ein Amt aufzugeben, das ihm, wie er zu Kronprinz Rupprecht am 4. November 1918 sagte,

102 Rupprecht, In Treue fest (wie Anm. 7), Bd 2, S. 473 (Eintrag vom 4.11.1918). 
»von Gott geworden und das er sich nicht beigelegt. Sollte er gestürzt werden, dann gebe es eben keine Hohenzollern mehr auf dem Throne [...] und dann solle Deutschland nur sehen, was aus ihm werde. «103

Kronprinz Rupprecht sah das Ganze nüchterner und politischer; er war längst der Ansicht, der Kaiser müsse abdanken. ${ }^{104}$ Obwohl er sich, als Thronfolger, schwertat, den Rücktritt des Kaisers zu fordern, hatte er doch seit Längerem eine sehr kritische Meinung über ihn entwickelt und ihm immer wieder fehlende Ernsthaftigkeit vorgeworfen. (»Und was tut der Kaiser? Er lässt sich allmorgentlich von seinem Friseur eine Locke auf seinen Scheitel brennen. « $^{105}$ ) Jetzt setzte Wilhelm II. in seinem beispiellosen Egozentrismus lieber auf den Versuch, seine Macht notfalls in einem Bürgerkrieg zu verteidigen. Die Lage geriet dadurch außer Kontrolle, und hinzu kam noch die Revolution in der Flotte, die sich rasch im Reich ausbreitete. Während Kronprinz Rupprecht noch im Hauptquartier seiner Heeresgruppe in Brüssel war, brach in Bayern am 7. November 1918 die Revolution aus. Der unabhängige Sozialdemokrat Kurt Eisner übernahm die Regierung und Ludwig III. floh. ${ }^{106}$ Als Kronprinz Rupprecht am 8. November morgens am Telefon erfuhr, dass in Bayern die Republik ausgerufen worden war, meinte er: »Gerade in München, wo dies am wenigsten zu erwarten stand! «107

Er hatte offenbar bis dahin nicht geglaubt, dass die bayerische Monarchie in Gefahr sei. Hingegen hatte der deutsche Kronprinz Wilhelm seine Chancen auf die Thronfolge schwinden sehen. Am 4. November hatte er Rupprecht aufgefordert, einen Schritt der Prinzen zugunsten des Kaisers und gegen die Abdankungsforderung zu unternehmen - was Rupprecht für aussichtslos hielt. Und am 8. November rief Wilhelm erneut an, war «äußerst besorgt" und sprach davon, »im Cylinderhut in der Schweiz promenieren zu müssen «. ${ }^{108}$

Die Regierung in Berlin erzwang am 9. November 1918 schließlich die Abdankung des Kaisers, der sich am nächsten Tag in die Niederlande absetzte. Kronprinz Rupprecht protestierte unterdessen gegen die Revolution in Bayern und verlangte, das Volk solle die Gelegenheit erhalten, in freier Volksabstimmung über seine zukünftige Staatsform zu entscheiden. ${ }^{109}$ Die Revolution erlebte er in seinem letzten Hauptquartier in Brüssel. Er sah plündernde deutsche Soldaten in

103 Ebd.

104 Ebd., S. 467 (Eintrag vom 26.10.1918); S. 470 (30.10.1918); S. 471 (2.11.1918).

105 BayHStA, GHA, NL Rupprecht, Nr. 707, Kriegstagebuch.

106 Dazu März, Das Haus Wittelsbach (wie Anm. 4), S. 486-503.

107 Weiß, Kronprinz Rupprecht (wie Anm. 1), S. 163.

108 BayHStA, GHA, NL Rupprecht, Nr. 708, Kriegstagebuch, Eintrag vom 8.11.1918.

109 Sendtner, Rupprecht von Wittelsbach (wie Anm. 4), S. 407. 
Brüssel und notierte in seinem vorletzten Tagebucheintrag: "Zum ersten Mal in meinem Leben schäme ich mich, ein Deutscher zu sein." Er weigerte sich auch, seine Macht als Oberbefehlshaber mit einem Soldatenrat zu teilen, und legte am 11. November 1918, dem Tag des Waffenstillstands, sein Kommando nieder. Dies war nicht zwingend nötig; Herzog Albrecht, Prinz Leopold und auch Hindenburg blieben im November 1918 auf ihrem Posten als Oberbefehlshaber und Generalstabschef und verließen ihre Stäbe nicht. Auch Kronprinz Rupprecht hätte bei seinem Stab bleiben können; stattdessen ging er mit einem falschen Pass, den er über die spanische Botschaft bekommen hatte, in die Niederlande, von wo er sich eigentlich so schnell wie möglich nach Bayern begeben wollte. Dort blieb er dann fast zwei Wochen, ohne dass die Gründe für seinen langen Aufenthalt wirklich transparent wurden, jedenfalls kaum eine schmeichelhafte Deutung zulassen. Wahrscheinlich schreckten ihn das Chaos und die Unklarheit in Deutschland ab. ${ }^{110}$ Erst als der Prinz erkannt wurde, entschloss er sich zur Flucht nach Deutschland: der arrangierte Grenzübergang erfolgte auf einer Rangierlokomotive. Als er Ende November in Bayern ankam, waren die Ereignisse über ihn und die Monarchie aber bereits hinweggegangen. Kronprinz Rupprecht war Privatmann - bayerischer und preußischer Generalfeldmarschall a.D. und ehemaliger Thronfolger.

\section{Reflexion nach dem Kriege}

Der Krieg der Prinzen hatte für Rupprecht mit dem Verlust seiner Thronansprüche und damit seiner Lebensaufgabe geendet, und es war angesichts seiner Erziehung und Persönlichkeit nicht überraschend, dass die Frage, ob und wie er diese Entwicklung revidieren könne, sein weiteres Leben dominierte. Die Restauration der bayerischen Monarchie stand, bis zu seinem Lebensende, im Zentrum seines Denkens. Er lehnte aber jeden Putsch, jede gewaltsame Restauration ab und wollte nur legal und in Übereinstimmung mit dem Volkswillen an die Macht zurückkehren. Bis zu seinem Tod war Rupprecht auch mit den politischen Folgen des Ersten Weltkriegs beschäftigt. Er glaubte nicht an die »DolchstoßLegende ${ }^{111}$ in ihrer nationalistischen Form, sondern machte, bei scharfer Ablehnung der Revolution von 1918, »Fehler unserer Politik wie der Obersten Heeresleitung « für die Niederlage verantwortlich. ${ }^{112}$ Damit interpretierte er die Abläufe

110 Weiß, Kronprinz Rupprecht (wie Anm. 1), S. 164-166 und S. 175.

111 Dazu: Boris Barth, Dolchstoßlegenden und politische Desintegration. Das Trauma der deutschen Niederlage im Ersten Weltkrieg, 1914-1933, Düsseldorf 2003 (= Schriften des Bundesarchivs, 61).

112 Weiß, Kronprinz Rupprecht (wie Anm. 1), S. 178. 
genauso wie zu Kriegszeiten; so hatte er beispielsweise am 13. Oktober 1918 geschrieben: „Das ganze Heer hat den Krieg satt und ist erschöpft, jedermann, abgesehen von einigen Starrköpfen, sieht ein, dass es nutzlos wäre, den Krieg weiterzuführen. «113

Nach 1918 kreisten die Gedanken des Prinzen, darin typisch für seine Zeitund seine Standesgenossen, vor allem um die Schlachten des Krieges, um verpasste militärische Chancen und um die Frage, was politisch oder operativ hätte besser gemacht werden können. ${ }^{114}$ Er selbst sah sich frei von Schuld. Als die Alliierten nach Artikel 228 die Auslieferung von Kriegsverbrechern verlangten, um sie vor Gericht zu stellen, und sein Name auf der Liste war, erklärte er sich bereit, sich freiwillig zu stellen, da er ein »völlig reines Gewissen« habe, »indem ich mir keines Verstoßes gegen die Kriegsgebräuche und die Regeln des Völkerrechts bewusst bin «. ${ }^{115}$ Er wurde aber nicht von den Alliierten, sondern stattdessen vor dem Reichsgericht in Leipzig angeklagt und von den Vorwürfen Gefangenentötungen und Verwüstung französischen Gebiets - freigesprochen. ${ }^{116}$

\section{Kronprinz Rupprecht von Bayern im Ersten Weltkrieg - eine verdiente positive Wertung?}

Es bleibt, ein kurzes Fazit von Kronprinz Rupprechts Handeln im Ersten Weltkrieg zu ziehen. Er hatte als bayerischer Thronfolger, als Generalfeldmarschall und Oberbefehlshaber einer Heeresgruppe sehr weit oben in der militärischen und politischen Hierarchie gestanden. Was hatte er bewegen können? Schließlich stand er fast den gesamten Krieg über in Daueropposition zu jenen, die für Strategie und Kriegführung politisch und militärisch verantwortlich waren.

Seine Opposition gegen Moltke hatte keine Wirkung mehr, da dieser schon Mitte September 1914 von seinem Posten abgelöst wurde. Auch seine Opposition gegen Falkenhayn und seine Forderung nach einer anderen Strategie blieben lange folgenlos. Sein Wunsch, Falkenhayn möge entlassen werden, fand erst in der Krise des Sommers 1916 seine Erfüllung, aber eher als Folge offenkundiger Fehler Falkenhayns, wie der Fehleinschätzung von Rumäniens Kriegsbereitschaft, und im Zusammenwirken mit vielen anderen Akteuren, zu denen Reichs-

113 BayHStA, GHA, NL Rupprecht, Nr. 708, Kriegstagebuch, Eintrag vom 13.10.1918.

114 Charakteristisch dafür ist der Briefwechsel mit Kuhl, der bis zu Rupprechts Tod im Jahr 1955 fortdauerte. BayHStA, GHA, NL Rupprecht, Nr. 724f.

115 Weiß, Kronprinz Rupprecht (wie Anm. 1), S. 174.

116 Ebd., S. $176 \mathrm{f}$. 
kanzler von Bethmann Hollweg, Hindenburg, Ludendorff und Teile der kaiserlichen Umgebung gehörten. ${ }^{117}$ Auch in der Ära Ludendorff konnte Rupprecht seine Ansichten nicht zur Geltung bringen, vor allem nicht seinen Vorschlag, auf den Westangriff $1918 \mathrm{zu}$ verzichten und eine Verhandlungslösung zu suchen.

Warum konnte sich Rupprecht in diesen Fragen nicht durchsetzen? Die Antwort muss mehrere Faktoren berücksichtigen. Erstens war Kronprinz Rupprecht als Soldat nicht unersetzlich. Er war in Bayern beliebt, aber er wurde zu keiner Zeit des Krieges als erstrangige und unverzichtbare strategische Begabung angesehen. Daher blieben auch seine Rücktrittsdrohungen, wie etwa im Zusammenhang mit »Alberich«, wirkungslos, denn notfalls hätte die deutsche Führung auf Rupprecht verzichtet. Als Kronprinz war er auch politisch kein Schwergewicht. Nur das perfekte Zusammenspiel mit seinem Vater, König Ludwig III., hätte seinen Interventionen vielleicht das nötige Gewicht verleihen können. Drängende Vorschläge des bayerischen Königs beim Kaiser hätten nicht unbeachtet bleiben können. Doch Ludwig III. und Rupprecht arbeiteten in den großen Fragen des Krieges eher gegenals miteinander. Und auch für die politischen Führer des Reiches, von Bethmann Hollweg bis Hertling, war Rupprecht allenfalls ein Bundesgenosse in Fragen, die von ihren eigenen Interessen und Einschätzungen gelenkt wurden, wie im Fall der Opposition gegen Falkenhayn.

Rupprecht war energisch und hielt auch mit hartnäckiger Konsequenz an seinen Ansichten fest, aber seine Einflussmöglichkeiten blieben aus diesen Gründen letztlich begrenzt. Hinzu kommt, dass der Prinz seine Emotionen nicht ausreichend unter Kontrolle hatte und seine Abneigungen wiederholt sein Urteilsvermögen beeinträchtigten. Hier wäre beispielsweise Rupprechts Unfähigkeit zu nennen, seine Opposition gegen Falkenhayn und dessen Strategie von seiner massiven persönlichen Antipathie zu trennen. Außerdem war Rupprecht von übergroßer Empfindlichkeit in Statusfragen, wenn es um seine Person und ganz besonders, wenn es um die Stellung Bayerns ging. All das reduzierte zusätzlich seine Wirkungsmöglichkeiten in der ersten Kriegshälfte.

Andererseits zeichnete sich Rupprecht durch Ernsthaftigkeit und Pflichtbewusstsein aus - was ihn beispielsweise von Wilhelm II. (und auch von dessen Sohn) unterschied. ${ }^{118}$ Zudem bewies er in der zweiten Kriegshälfte einen »nüchternen Verstand « - einen Realismus, der vielen in der deutschen Führung fehlte. Seine Sicht auf die Dinge wirkt sehr viel realistischer als die anderer Führungspersönlichkeiten des Wilhelminischen Deutschland. Hier könnten etwa die

117 Dazu neben Afflerbach, Falkenhayn, auch Karl-Heinz Janßen, Der Wechsel in der Obersten Heeresleitung 1916. In: Vierteljahrshefte für Zeitgeschichte, 4/1959, S. 337-371.

118 Pöhlmann, Kriegsgeschichte und Geschichtspolitik (wie Anm. 10), S. 305f. 
Wankelmütigkeit und das krude Gottesgnadentum Wilhelms II., ${ }^{119}$ der sture und »militaristische« Nationalismus und das Schwarz-Weiß-Denken des »Willensmenschen « Ludendorff, ${ }^{120}$ der königstreue und gleichzeitig ebenso selbstsüchtige wie oft wirklichkeitsfremde Optimismus eines Hindenburg ${ }^{121}$ oder die protestantische Prädestinationslehre, welcher der Chef des Militärkabinetts, Generaloberst Moriz von Lyncker, anhing, ${ }^{122}$ erwähnt werden. Kronprinz Rupprecht hatte zwar keine perfekten Lösungsrezepte für die strategischen Dilemmata des Deutschen Reiches entwickelt, ${ }^{123}$ aber doch in der zweiten Kriegshälfte die Situation sehr viel zutreffender beurteilt als Regierung und OHL. Ob seine eigenen Vorstellungen im Fall ihrer Umsetzung einen besseren Kriegsausgang hätten erreichen können, muss offen bleiben. Sicher ist jedoch, dass die von ihm beschworene energischere Friedenspolitik keinesfalls von Nachteil gewesen wäre.

Rupprecht unterschied sich von den anderen dynastischen Spitzen des Deutschen Reichs im Ersten Weltkrieg, was erklärt, dass das Urteil über den Prinzen in der Forschung so einhellig positiv ist. Golo Mann sah in dem Prinzen, der nie zur Herrschaft kommen sollte, sogar den potenziell besten der bayerischen Könige. ${ }^{124}$ Dieses Urteil muss man nicht teilen; der Prinz war kein geniales politisches oder militärisches Talent. Da Rupprecht in der zweiten Kriegshälfte aber einen moderaten und realistischen Kurs vertrat und auf politischen Ausgleich drängte, ist es nachvollziehbar, dass das Urteil über den letzten bayerischen Kronprinzen in der historischen Forschung positiv ausfällt.

\section{Nachsatz zur Edition der Kriegstagebücher des Kronprinzen}

Umso bedauerlicher ist es, dass die Hauptquelle, seine Tagebücher, so unverlässlich ediert ist. An eine gedruckte Neuedition ist, angesichts des schieren Umfangs

119 Kaiser Wilhelm II. als Oberster Kriegsherr während des Ersten Weltkrieges - Quellen aus der militärischen Umgebung des Kaisers 1914-1918. Bearb. und eingel. von Holger Afflerbach, München 2005 (= Deutsche Geschichtsquellen des 19. und 20. Jahrhunderts, 64), S. 35-38.

120 Dazu Nebelin, Ludendorff (wie Anm. 12) sowie der Klassiker zu Ludendorffs »Militarismus«: Gerhard Ritter, Staatskunst und Kriegshandwerk. Das Problem des "Militarismus« in Deutschland, 4 Bde, München 1954-1968, Bd 3 und Bd 4.

121 Dazu Pyta, Hindenburg (wie Anm. 12), passim.

122 Afflerbach, Wilhelm II. (wie Anm. 119), S. 107-111.

123 Dazu Afflerbach, »... eine Internationale der Kriegsverschärfung und der Kriegsverlängerung ...« (wie Anm. 62).

124 Weiß, Rupprecht (wie Anm. 1), S. 358. 
dieser Quelle, nicht $\mathrm{zu}$ denken. Hier soll zumindest auf das Ausmaß dieser Unverlässlichkeit hingewiesen werden. Der Aufwand stünde in keinem vertretbaren Verhältnis zum wissenschaftlichen Ertrag. Das Tagebuch allein geht derart ins Detail, dass dies den normalen Leser und Nutzer weit überfordern würde. Schon die drei Bände der stark gekürzten Edition, die etwa 20 bis 25 Prozent des handschriftlichen Manuskripts umfassen dürfte und fast alle Anlagen weglässt, sind sehr detailliert und auch fragmentarisch im Darstellungsstil. Dies trifft noch mehr auf das Original zu, das den Leser mit einer scheinbar endlosen Suada militärischer Einzelheiten konfrontiert. Auf der anderen Seite zeigt das Originaltagebuch sehr viel besser als die gedruckte Fassung, wie sehr der Kronprinz in seinen Anschauungen von Tag zu Tag schwankte und auch, welche Rolle beispielsweise Gefangenenaussagen für seine Beurteilung der strategischen Lage hatten.

Ein möglicher Ausweg, der dem Wunsch nach wissenschaftlicher Exaktheit ebenso nachkäme wie dem Verlangen nach vertretbarem Arbeitsaufwand, wäre die Präsentation des Tagebuchs in einer Onlineversion, die entweder die gedruckte Fassung einliest und unter Nutzung des Originals ergänzt und, wo nötig, berichtigt oder aber das im Geheimen Hausarchiv liegende handschriftliche, aber gut lesbare Original einscannt und als pdf präsentiert, um dem Historiker damit die Möglichkeit zu bieten, das Original zu nutzen oder aber die gedruckte Edition an wichtigen Stellen mit diesem vergleichen zu können. 